\title{
A review of transport market modeling using game-theoretic principles
}

\author{
Nicole Adler ${ }^{a, *}$, Amir Brudner ${ }^{a}$, Stef Proost ${ }^{b}$ \\ a School of Business Administration, Hebrew University of Jerusalem, Mount Scopus, Jerusalem 91905, Israel \\ ${ }^{\mathrm{b}}$ Department of Economics, KU Leuven, Naamsestraat 69, Leuven B-3000, Belgium
}

\section{A R T I C L E I N F O}

\section{Article history:}

Received 13 January 2020

Accepted 12 November 2020

Available online $\mathrm{xxx}$

\section{Keywords:}

Transportation

Game theory

\begin{abstract}
A B S T R A C T
Transport markets involve interactions between multiple groups of decision-makers, hence they are good candidates to be analyzed through the prism of game theory. The many models and algorithms published to date tend to reflect different academic disciplines, including operations research, economics and engineering approaches. Models published in the operations research oriented journals often involve large network components in order to provide relatively specific insights, building on Stackelberg, Wardrop and traffic assignment formulations. Game-theoretic models published in economics journals are frequently conceptual with stylized assumptions, such as Cournot, Bertrand and Hotelling, all of which have been applied to transportation markets. We present the more common models and highlight the differences in the equilibria outcomes drawing from the choice of model and beliefs of the players in the market. We discuss the most widely applied algorithms and formulations utilized to solve network-based transport markets. Finally, we review the published literature with real-world applications and discuss potential new areas yet to be explored substantially, including the analysis of multi-modal markets involving both competition and cooperation across transport modes.
\end{abstract}

(c) 2020 Published by Elsevier B.V.

\section{Introduction}

Game-theoretic modeling approaches combine multiple academic disciplines to create an understanding of a market. All the basic game-theoretic models have been applied to analyze transportation markets (Zhang, Su, Peng, \& Yao, 2010) and we present the underlying approaches and algorithms in this review. Furthermore, a wide range of transport policy issues have been analyzed from a game-theoretic perspective, covering urban public transport (Roumboutsos \& Kapros, 2008; Schiewe, Schiewe, \& Schmidt, 2019; Sun \& Gao, 2007), traffic assignment (Bell \& Cassir, 2002), and network reliability (Bell, 1999), to mode-specific questions (Adler, 2001; Harks, Schröder, \& Vermeulen, 2019; Ishii, Lee, Tezuka, \& Chang, 2013; Littlechild \& Thompson, 1977; Schipper, Nijkamp, \& Rietveld, 2007; Song \& Panayides, 2002) and multi-modal competition (Adler, Pels, \& Nash, 2010; Algaba, Fragnelli, Llorca, \& SánchezSoriano, 2019). Hence, we discuss some specific mode applications and finally turn to the multi-modal transport markets which have only recently begun to appear in the literature.

\footnotetext{
* Corresponding author.

E-mail addresses: msnic@huji.ac.il (N. Adler), brudner@mail.huji.ac.il (A.Brudner), stef.proost@kuleuven.be (S. Proost).
}

A game-theoretic representation of a transport market includes three basic elements (Gibbons, 1992):

1. the players involved in the market, including transport service operators such as taxi, bus, railway, freight shipper, airline and transportation network companies; infrastructure providers such as station operators, airports, air traffic control providers, road and bridge network providers and railway infrastructure companies, which may be public or private entities; regulators and government departments; and the passengers or travelers participating in the market.

2. the strategies available to each player, which may include network choice, fleet types, timetables, frequencies, fares, tolls and subsidies for transport operators. Regulators and government departments may be responsible for setting capacities, safety levels and investments. Passengers may choose a single or multi-modal route or not to travel. We refer to a "pure strategy" if a player chooses a single strategy consistently however a player may choose a set of strategies over a probability distribution known as a "mixed strategy".

3. the payoff received by each player per combination of strategies chosen by the set of stakeholders involved in the market, each optimizing their respective best-response functions, which reflects an adapted objective function. For transport operators the payoff could reflect profits, for bus 
and rail companies this could also include subsidies and for infrastructure managers this could represent cost minimization. Passengers minimize generalized travel costs and regulators are frequently defined as social welfare maximizers. Another alternative for regulators facing non-competitive transport markets is to introduce auctions that create competition for the market, a method frequently employed in bus markets to optimize the benefit-cost ratio.

One of the central concepts of game theory is the Nash equilibrium (Nash, 1951), a situation in which none of the players can improve their payoffs, given that all other players remain with their strategy. We define a Nash equilibrium in the following way: $\left(s_{1}^{*}, \ldots, s_{N}^{*}\right)$, where strategy $s_{i} \in S_{i}$, is a Nash equilibrium if for the utility $u_{i}$ for every player $i \in N$ :

$u_{i}\left(s_{i}^{*}, s_{N \backslash\{i\}}^{*}\right) \geq u_{i}\left(s_{i}, s_{N \backslash\{i\}}^{*}\right) \quad \forall s_{i} \in S_{i}$

where $s_{N \backslash\{i\}}$ are the optimal strategies of all players except $i$. The Nash equilibrium has many refinements and has proven compelling in understanding how market equilibria are created (Myerson, 1978).

We survey the basic game models relevant for the analysis of transportation markets and divide them into four categories (i) common oligopoly, (ii) spatial games, (iii) traffic assignment games and (iv) auctions. Common oligopoly models include duopoly games such as Cournot (1838) and Bertrand (1883) in which the players simultaneously set the quantities (such as frequencies) or prices (such as fares) respectively in order to maximize their profits. We also describe Stackelberg competition (Von Stackelberg, 1934) in which players set their quantities sequentially, with the first player acting as leader, and a second player acting as the follower. The second set of spatial games include Hotelling (1929) which takes into account the location of the services that various transportation providers offer. Unlike Hotelling who assumes diversity in linear space, Salop (1979) assumes circular diversity and this difference alone may lead to a different market equilibrium. The third set of traffic assignment models account both for the spatial and time distribution of traffic. Wardrop equilibria (Wardrop, 1952) under certain conditions are considered equivalent to the Nash equilibrium in transportation (Fisk, 1984) because no driver is able to reduce their travel time by changing routes (Hollander \& Prashker, 2006). The bottleneck model is one of the fundamental methods for the analysis of congestion, introduced by Vickrey (1969) alongside congestion games, introduced by Rosenthal (1973) and later generalized by Monderer and Shapley (1996) to potential games. Subsequently, we describe the demand-side modeling approaches which span simple linear functions to discrete choice functions (McFadden, 1973) that may account for multiple transport attributes.

In game theory, one of the frequent assumptions is that players act rationally, hence individuals or firms facing several alternatives will choose to maximize their utility or payoff. It is often assumed that the individual is fully informed about the payoffs and risks (travel time or travel cost) and is in a position to determine the most appropriate action (route or mode choice). Easing such assumptions leads to the theory of bounded rationality which involves modeling uncertainty, incomplete information and computational limitations (Simon, 1972). Furthermore, individual rationality is not necessarily sufficient to achieve collective rationality (Sandler, 1992) and might even lead to collective irrationality (Arrow, 1963). For example, individual rational behavior may be to search for cheap on-street parking as compared to more expensive off-street car parks. This behavior generates congestion, accidents and pollution (Shoup, 2006) and is irrational from the collective perspective. In the engineering literature, user equilibrium versus system optimal approaches are frequently analyzed and the cost of decentralization is usually referred to as the 'price of anarchy' in the computer science literature (Koutsoupias \& Papadimitriou, 1999; Nisan, Roughgarden, Tardos, \& Vazirani, 2007).

Another relevant aspect of game theory is the order of strategy implementation. The most basic, static game assumes that all players choose their strategy simultaneously. The dynamic, or sequential-move game, considers time or repetition which permits greater cooperation in general (Aumann \& Shapley, 1994). We note that a change in the order of play in a sequential-move game may lead to alternative equilibria outcomes (Zhang et al., 2010). The transition from stage to stage may include stochastic demand such that the states over which the game evolves are probabilistic (Shapley, 1953a). The choice of model thus depends on whether the strategies are relevant in the shorter term (for example collaboration over fares) or longer term (for example auctioning buildoperate-transfer infrastructure, such as a road or airport project).

Nash developed both competitive (Nash, 1951) and cooperative (Nash, 1953) game-theoretic models in the 1950's and concepts from both streams have proven relevant to the understanding of transport markets. Coalition games focus on superadditivity and the probability of a group of operators to cooperate effectively. A coalition game attempts to answer two questions: (i) Which coalitions will be formed? and (ii) How should the payoff be divided between members of the coalitions such that no operator would find it worthwhile to deviate from the existing agreement (Shoham \& Leyton-Brown, 2008). Such games are relevant if considering the auctioning of urban transport services. An interesting cooperative game-theoretic concept is the core (Gillies, 1953; Von Neuman \& Morgenstern, 1944), which assesses the set of all feasible payoffs that no operator, or coalition of operators, could improve upon as a result of regrouping (Kannai, 1992). A similar concept, known as the contract-curve, was first discussed by Edgeworth back in 1881. The Shapley value, (Shapley, 1953b) attempts to divide the payoff such that each operator in a coalition receives their expected marginal contribution to the coalition (Hart, 1989). Another method for dividing the payoff among the members of a coalition is defined by the nucleolus of a game, first defined by Schmeidler (1969), which aims to minimize the maximum dissatisfaction of any operator in the coalition (Maschler, Peleg, \& Shapley, 1979). The latter two methods were applied to estimate the cost allocation in the planning of a cooperative supply chain for the logging industry (Frisk, Göthe-Lundgren, Jörnsten, \& Rönnqvist, 2010) and to estimate airport charges that cover the capital costs of building and maintaining a runway (Littlechild \& Thompson, 1977).

Since all forms of transportation involve multiple operators, including urban transport, freight markets, shipping and aviation, game-theoretic tools have been applied to shed light on existing equilibria outcomes and search for alternatives that may improve overall social welfare. Three review papers on game theory in transportation have been published to date, namely Fisk (1984), Hollander and Prashker (2006) and Zhang et al. (2010). The contribution of the current survey is that we first describe the modeling approaches drawing from operations research, economics, engineering and computer science in order to create a trans-disciplinary approach. Subsequently, we review publications with real-world applications to transportation markets. Most of the real world applications are relatively new and have been published over the last two decades. One reason could be that the modeling approaches are complicated and difficult to calibrate, However this type of modeling framework is very useful, both for the transport operators and for those involved in creating evidence-based policies.

The paper is organized as follows: In Section 2 we describe the basic game-theoretic models that are relevant for the analysis of transport networks. In Section 3 we describe models aimed at capturing demand behavior, a key variable in transport network 
games. Section 4 describes alternative formulations and algorithms used to solve the game-theoretic models. In Section 5 we survey the published literature for all modes and conclude the review with some ideas on potential future research in Section 6.

\section{Transportation networks modeling approaches}

In this section, we describe models that may be applied to analyze transportation markets in order to shed light on the interactions between transport operators. The interactions may be demand-side, determining origin-destination flows and market share, or supply-side through frequencies and fares given capacity constraints and economic limitations. Game-theoretic network approaches are relevant to all transport markets and imply the need to consider both positive and negative externalities such as mobility and access to the job market in addition to pollution, congestion and accidents. We present four groups of models in this section (i) common oligopoly models; (ii) spatial models; (iii) traffic assignment models; and (iv) auctioning of transportation infrastructure and services.

\subsection{Common oligopoly models}

The most common oligopolistic models include Cournot, where operators compete over quantities, Bertrand, where the competition is over fares, and Stackelberg, in which a leader set quantities and a follower attempts to compete. The choice of model depends on the form of competition in the market and the relative importance of the transport operators. For example, Brander and Zhang (1990) tested airline markets and found that duopoly routes from Chicago were well described by Cournot outcomes. The data collected covered 33 routes served by American Airlines and United, both of which use Chicago O'Hare as their hub. On the other hand, at airports controlled by hub carriers, the incumbent carrier often leads the market and the remaining carriers act as followers with lower frequencies and airfares (Borenstein, 1989), suggesting that Stackelberg games may be more relevant. Saeed and Larsen (2010) analyzed competition between seaports using a Bertrand model, arguing that ports do not determine quantities, rather prices, in an attempt to attract customers. Kaselimi, Notteboom, and De Borger (2011) analyze seaport competition using a Cournot model, by collapsing a two stage game in which the container terminal capacity decision is optimized first and then the terminals compete in price in a second stage (Kreps \& Scheinkman, 1983). As we show in Section 2.1.4, the choice of model will impact the equilibria outcome estimates, hence conclusions of the analysis. Furthermore, the number of competitors will also impact the equilibria outcome, for example in the airline industry, the number of competitors in short haul markets tends towards duopolies or monopolies whereas medium to long haul markets tend towards four airlines on average (Borenstein, 1992; Brander \& Zhang, 1990).

\subsubsection{Cournot}

The French philosopher and mathematician Antoine Augustin Cournot first introduced what we now call 'Cournot competition' (Cournot, 1838) $)^{1}$ in order to describe the competition between two dominant suppliers (duopoly) of spring water. In Cournot competition, the transport operators, infrastructure suppliers or freight companies set the quantities produced such as capacity or frequency and the charges or fares are subsequently derived. To demonstrate the model, consider a simple duopoly market in which two railway operators compete to offer service between two

\footnotetext{
${ }^{1}$ In his 1838 book 'Recherches sur les Principes Mathematiques de la Theorie des Richesses', Researches Into the Mathematical Principles of the Theory of Wealth.
}

cities. Assuming for simplicity a unitary price elasticity, the demand function is given by:

$Q=a-p$

where $p$ is the fare and $Q$ is the total number of seats supplied by the two firms $i$ and $j$. $a$ represents the maximum demand at zero price. The total quantity $Q$ consists of the seats supplied by both firms. Each operator maximizes their individual profit:

$\max _{q_{i}} \pi_{i}=\left[a-\left(q_{i}+q_{j}\right)-c\right] q_{i}$ whereby $Q=q_{i}+q_{j}$

where $c$ is the cost per seat supplied if we assume that both firms have an identical, linear cost function. The first order conditions for firm $i$ with respect to $q_{i}, \partial \pi_{i} / \partial q_{i}=0$ yields:

$q_{i}=\frac{a-q_{j}-c}{2}$

Assuming that the firms are identical:

$q_{i}=q_{j}=\frac{a-c}{3}$

The price per seat is therefore: $p=\frac{a+2 c}{3}$ and the profit of firm $i$ is: $\pi_{i}=\frac{1}{9}(a-c)^{2}$. In reality, the cost function may be better defined as a non-linear step function corresponding to additional lanes on a road network or runway at an airport. However, as demonstrated for the energy industry, this might have a marginal effect on the results (Neuhoff et al., 2005).

\subsubsection{Bertrand}

Joseph Louis François Bertrand first discussed 'Bertrand competition' in a review of Cournot's 1838 book (Bertrand, 1883) by describing the firms as competing in prices such that the quantities are derived. Bertrand claimed that the result of Cournot is not an equilibrium because either firm could increase profits by undercutting the market price and serving the entire market. Subsequently, the other firm will respond with a price reduction and this would continue ad infinitum. Bertrand's description was mathematically formalized a few years later by Francis Edgeworth (Edgeworth, 1889). He proved that under price competition between identical players, the price will equal the cost:

$p=c$

which yields a quantity, such as seat capacity, of:

$q_{i}=\frac{a-c}{2}$

and a profit of zero. Zhou and Lee (2009) model Bertrand duopoly competition between firms that provide transportation services between two locations. The service requires transport equipment with repositioning if the demand is unbalanced. They prove that for symmetric firms, a unique Bertrand Nash equilibrium exists and that unbalanced demand does not necessarily mean lower profits. If the demand is fixed and one market is less sensitive to prices, the imbalance means that greater demand in a less sensitive market could cover the repositioning costs.

Alternatively, under differentiated Bertrand competition, transport operators also compete over the quality of their service, for example first and second class carriages. Consequently, the fare may be higher than the marginal cost, thus generating positive profits. In this case, demand for firm $i$ 's seats is given by:

$q_{i}=a_{i}-b_{i i} p_{i}+b_{j i} p_{j}$

where $a_{i}$ is the maximum demand for firm $i, b_{i i}$ is firm $i$ 's price coefficient with respect to its own price and $b_{j i}$ is the cross price coefficient with respect to firm $j$ 's fare. Firm $i$ maximizes its profit as follows:

$\max _{p_{i}} \pi_{i}=\left(p_{i}-c_{i}\right)\left(a_{i}-b_{i i} p_{i}+b_{j i} p_{j}\right)$ 
Given the first order condition for firm $i$ with respect to $p_{i}$, $\partial \pi_{i} / p_{i}=0$, and assuming symmetry (i.e. $a_{i}=a_{j}=a, b_{i i}=b_{j j}=b$ and $\left.b_{j i}=b_{i j}=\bar{b}\right)$, the best response function for firm $i$ is:

$p_{i}\left(p_{j}\right)=\frac{a+b c_{i}+\bar{b} p_{j}}{2 b}$

In the context of transportation, a key consideration is congestion which is defined in several ways in the literature. Caves (2005) defines congestion as the time lost per vehicle per kilometer compared to average conditions. Alternatively, the comparator could be drawn from free flow conditions. Stopher (2004) defines congestion as the difference between demand for a road segment and the flow capacity, a definition that has been adopted in the traffic engineering literature. Stopher distinguishes between recurring and non-recurring congestion whereby the former occurs on a regular time basis and the latter results from a specific event, such as an accident. de Palma and Leruth (1989) adapt differentiated Bertrand to include congestion levels. They show that congestion weakens the impact of competition because lower prices increase congestion, leading to a less attractive service. Therefore, firms might benefit from congestion because the phenomenon softens price competition. They extend the classic Bertrand equilibria outcome to account for capacity and congestion as follows:

$u_{i}=a-p_{i}-\theta \frac{q_{i}}{f_{i}}$

where $u_{i}$ is the traveler's utility from operator $i, f_{i}$ is the capacity of firm $i, \frac{q_{i}}{f_{i}}$ is the level of congestion and $\theta$ is the traveler's willingness-to-pay in order to avoid congestion. However, we note that this model assumes that congestion is independent of the service provided by the other transport operator. This could be considered a point of weakness if both firms utilize the same infrastructure to deliver the service. The profit of operator $i$ is given by:

$\pi_{i}=p_{i} q_{i}-c\left(f_{i}\right)$

The cost of production is a function of the specific operator's capacity. Assuming $a$ is large enough such that passengers choose to travel only once, the equilibrium is as follows:

$p_{i}+\theta \frac{q_{i}}{f_{i}}=p_{j}+\theta \frac{q_{j}}{f_{j}}$

Equation (2.11) is known as the Wardrop Principle (de Palma \& Leruth, 1989). Normalizing the total demand to 1 (i.e. $q_{i}+q_{j}=Q=$ 1) together with the first order conditions gives the equilibrium fare as:

$p_{i}=\frac{\theta\left(2\left(1 / f_{j}\right)+\left(1 / f_{i}\right)\right.}{3}$ and the equilibrium demand:

$q_{i}=\frac{2\left(1 / f_{j}\right)+\left(1 / f_{i}\right)}{3\left[\left(1 / f_{i}\right)+\left(1 / f_{j}\right)\right]}$

with positive equilibrium profit:

$\pi_{i}=\frac{\theta\left(2 f_{i}+f_{j}\right)^{2}}{9\left(f_{i}+f_{j}\right) f_{i} f_{j}}-c\left(f_{i}\right)$

\subsubsection{Stackelberg}

Heinrich Freiherr von Stackelberg first presented his model of leadership competition in his 1934 book (Von Stackelberg, 1934). ${ }^{2}$ In the duopolistic Stackelberg market, a leader determines capacity and a follower responds, similar to the Cournot assumption. Solving a Stackelberg game begins with the second stage in which the follower $(j)$ sets quantities whilst taking into account the leader's

\footnotetext{
2 'Marktform und Gleichgewicht', Market Structure and Equilibrium. The book was translated by Damien Bazin (Von Stackelberg, 2010).
}

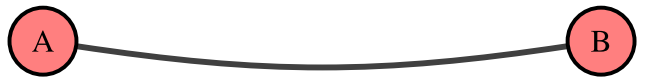

Fig. 1. The network.

quantity $(i)$ choices given in Eq. (2.2). The leader, firm $i$, maximizes profits accordingly:

$\max \pi_{i}=\left[a-\left(q_{i}+\frac{a-q_{i}-c}{2}\right)-c\right] q_{i}$

First order conditions yield:

$q_{i}=\frac{a-c}{2}, \quad q_{j}=\frac{a-c}{4}$

The price is then derived:

$p=\frac{a+3 c}{4}$

and the profits are $\pi_{i}=\frac{1}{8}(a-c)^{2}, \pi_{j}=\frac{1}{16}(a-c)^{2}$ for leader $i$ and follower $j$ respectively. Consequently, under Stackelberg competition, the incumbent, or leader, has an advantage over the follower.

Stackelberg competition may be viewed as a constrained optimization problem (Fisk, 1984). In a two player game, each operator minimizes the cost function $c_{i}\left(x_{1}, x_{2}\right)$ in which the cost to one operator is also impacted by the competitor, for example through congestion. In a Nash non-cooperative game, the equilibrium solution is derived by simultaneously solving $\min _{x_{i}} c_{i}\left(x_{1}, x_{2}\right)$ per player. Equivalently, we could solve the constrained problem $\min _{x_{1}, x_{2}} c_{1}\left(x_{1}, x_{2}\right)$ subject to the constraint $c_{2}\left(x_{1}, x_{2}\right)=\min _{y} c_{2}\left(x_{1}, y\right)$. Fisk describes an optimization problem in which a regulator optimizes network performance such as minimum total travel time or gas consumption and in the second stage, travelers respond by choosing their routes on the network to minimize their personal cost.

Stackelberg has also been extended in many directions, for example Sherali, Soyster, and Murphy (1983) study a market where one leader and $N$ followers engage in a Stackelberg game and the followers engage in a Cournot game between themselves. Miller, Tobin, and Friesz (1991) formulate a Stackelberg game in order to analyze a production and shipping strategy. They formulate an aggregate reaction function for the Cournot competitors given the strategy of the leader. In the next step, they use a linear approximation of the reaction function in the Stackelberg profit maximization problem and repeat the process until no significant improvement is achieved by any of the players.

\subsubsection{Illustrating the equilibria outcomes of the various modeling approaches}

Consider a simple network as a case study to highlight the differences between the approaches and their impact on the results. The network is presented in Fig. 1 in which two freight companies compete while offering an identical delivery service. A unit delivered requires one standard truck and the service is distributed uniformly over time.

The demand function is given in Eq. (2.17).

$Q=280-P$

where $P$ is the price and $Q$ is the total quantity supplied by the two companies i.e. $Q=q_{1}+q_{2}$. We consider two scenarios, with and without congestion. The marginal cost of the two identical freight companies is given by Eq. (2.18) without congestion and Eq. (2.19) with congestion.

$M C=40$

The second scenario defines the network as subject to congestion and the marginal cost is:

$\overline{M C}=40+40 \frac{Q}{C a p}$ 
Table 1

\begin{tabular}{|c|c|c|c|c|c|c|}
\hline Model & Decision Variables & $\boldsymbol{P}$ & $Q$ & Firm 1 & Firm 2 & Consumer Surplus \\
\hline Cournot & $q_{1}, q_{2}$ & 120 & 160 & $q_{1}=80 \pi_{1}=6,400$ & $q_{2}=80 \pi_{2}=6,400$ & 12,800 \\
\hline Cournot congested network & $q_{1}, q_{2}$ & 138 & 142 & $q_{1}=71 \pi_{1}=5,614$ & $q_{2}=71 \pi_{2}=5,614$ & 10,082 \\
\hline Bertrand & $p_{1}, p_{2}$ & 40 & 240 & $q_{1}=120 \pi_{1}=0$ & $q_{2}=120 \pi_{2}=0$ & 28,800 \\
\hline Bertrand congested network & $p_{1}, p_{2}$ & 68 & 212 & $q_{1}=106 \pi_{1}=0$ & $q_{2}=106 \pi_{2}=0$ & 22,472 \\
\hline Stackelberg & $q_{1}, q_{2}$ & 100 & 180 & $q_{1}=120 \pi_{1}=7,200$ & $q_{2}=60 \pi_{2}=3,600$ & 16,200 \\
\hline Stackelberg congested network & $q_{1}, q_{2}$ & 121 & 159 & $q_{1}=106 \pi_{1}=6,339$ & $q_{2}=53 \pi_{2}=3,169$ & 12,641 \\
\hline
\end{tabular}

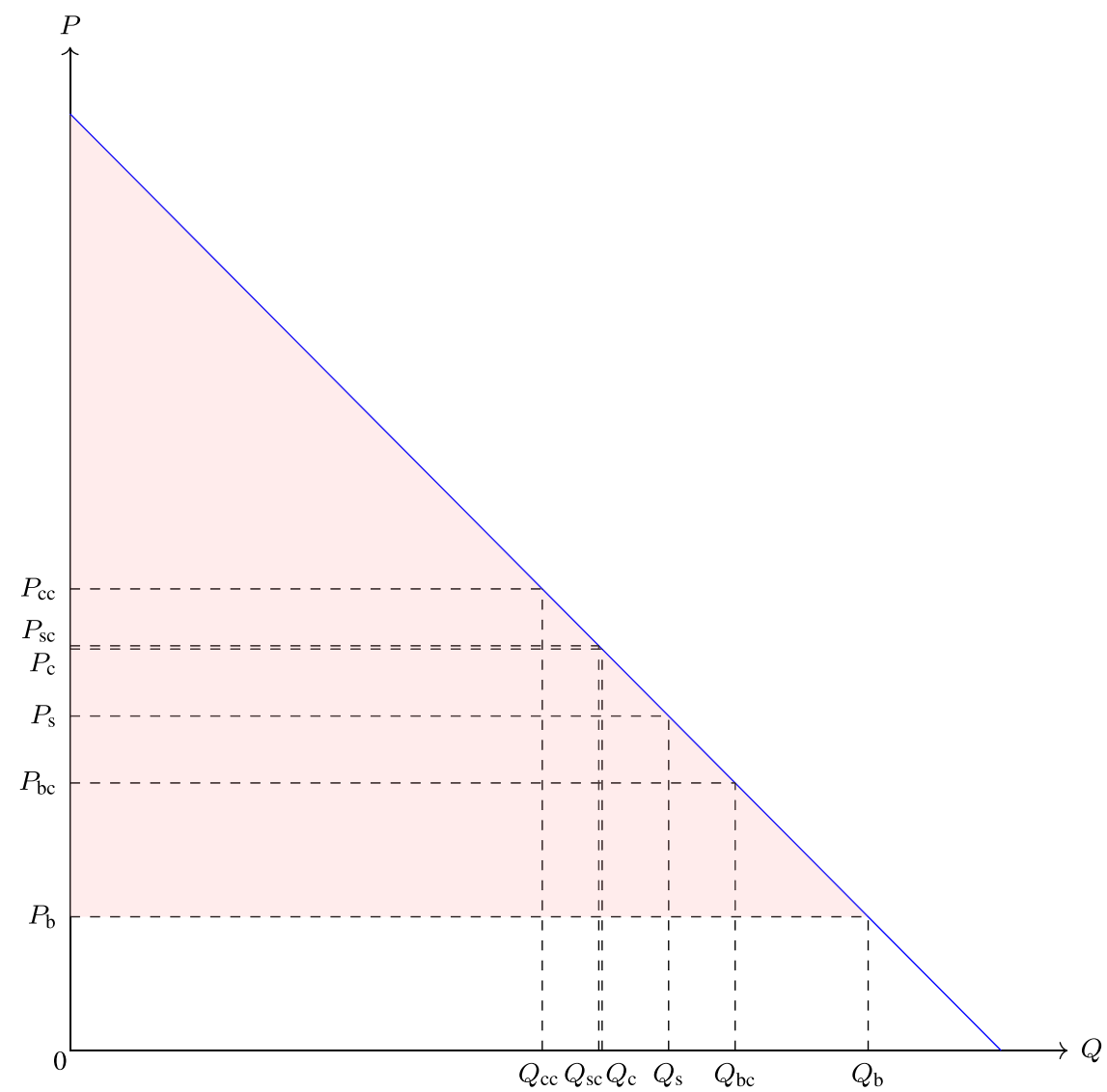

Fig. 2. Consumer surplus under different scenarios. Subscripts are c-Cournot, cc-Cournot with congestion, b-Bertrand, bc-Bertrand with congestion, s-Stackelberg, scStackelberg with congestion.

where Cap is the network capacity in terms of trucks per unit of time. In this example $C a p=300$. A summary of the results is presented in Table 1.

We first analyze network competition under Cournot according to which the freight companies compete over quantities. The inverse demand function is given by:

$P=280-Q=280-q_{1}-q_{2}$

Under the no congestion scenario, the profit of company 1 is:

$\pi_{1}=\left(280-q_{1}-q_{2}\right) q_{1}-40 q_{1}$

First order conditions with respect to $q_{1}$ yield $q_{1}=120-\frac{1}{2} q_{2}$ and the total quantity under Cournot competition is $Q_{c}=160$ with a price of $P_{c}=120$. The consumer surplus is given by the area of the triangle under the linear demand function and above the price dotted line (see Fig. 2):

$\mathrm{CS}_{c}=\frac{\left(280-P_{c}\right) Q_{c}}{2}=\frac{(280-120) 160}{2}=12,800$
Taking into account congestion, Eq. (2.21) is replaced as follows:

$\pi_{1}=\left(280-q_{1}-q_{2}\right) q_{1}-\left(40+40 \frac{q_{1}+q_{2}}{300}\right) q_{1}$

Under the assumption of linear congestion, the first order condition leads to lower quantities, $q_{1}=106-\frac{1}{2} q_{2}$ resulting in $Q_{c c}=$ $142, P_{c c}=138$ and $\mathrm{CS}_{c c}$ is reduced to 10,082 accordingly. In this case, the freight companies offer lower quantities for higher prices when the network is congested. It is apparent that both producers and consumers lose when the system is congested, although we have not considered the fixed cost of designing and constructing the infrastructure that would enable an increase in capacity Cap.

As Bertrand (1883) suggested, the price of 120 derived from the Cournot solution is not an equilibrium because either freight company could reduce the price to 119 and capture the entire market. The second company will respond with a price of 118 and so on until both companies reach a price equal to the marginal cost of 40 . Let us then turn to analyze the Bertrand model where the freight companies set their prices. As shown in Table 1, competition under Bertrand is more extensive as the total quantity 


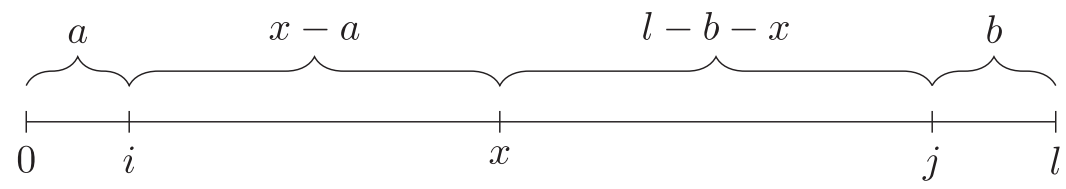

Fig. 3. Hotelling linear city.

delivered to the market is $Q_{b}=240$ with a price of $P_{b}=40$ and the entire profit is subsumed into the consumer surplus. Assuming a congested network in which $P=280-Q=40+40 \frac{Q}{300}=\overline{M C}$ and $Q_{b c}=212$, freight forwarder (i.e. consumer) surplus drops to 22,472 as each unit is priced at $P_{b c}=68$. The full loss due to congestion is thus passed on to the forwarders who now have a different cost and the freight companies continue to achieve no profits. Only if the companies are able to differentiate their services will we see a positive profit outcome.

The case in which one freight company is considered the leader, denoted company 1 , and the other as the follower, company 2 , is analyzed through a Stackelberg game. The quantity produced by the follower, $q_{2}=120-\frac{1}{2} q_{1}$ ensures company 1 profits as follows:

$\pi_{1}=\left[280-q_{1}-\left(120-\frac{1}{2} q_{1}\right)\right] q_{1}-40 q_{1}$

and freight forwarder surplus as 16,200 as the total quantity delivered to the market is $Q_{S}=180$ at a price of $P_{S}=100$ per unit. When taking congestion into account, company 2's best response reduces to $q_{2}=106-\frac{1}{2} q_{1}$. Company 1 's profit in the congested game is given by:

$\pi_{1}=\left[280-q_{1}-\left(106-\frac{1}{2} q_{1}\right)\right] q_{1}-\left(40+40 \frac{q_{1}+106-\frac{1}{2} q_{1}}{300}\right) q_{1}$

leading to consumer surplus of 12,641 with lower quantity of $Q_{s c}=$ 159 at a price of $P_{S c}=121$ per unit. Consequently, the Stackelberg game leads to higher quantities and profits for the leader and less to the follower as compared to the classic Cournot simultaneous equilibria outcome, in particular when working in a congested market. Furthermore, consumer surplus is higher at the expense of the follower too. As depicted in the shading in Fig. 2, the smallest consumer surplus is achieved under the Cournot with congestion solution outcome and the largest under simple Bertrand.

Other differences between the models may also lead to alternative outcomes, for example due to regulatory contracts, levels of competition and alternative ownership forms. Jørgensen and Mathisen (2014) define goal functions in order to model profit maximizers separately from non-profit operators that maximize consumer surplus. They show that non-profit transport operators placing emphasis on consumer surplus may lead to lower, Cournot prices compared to those of Bertrand, that may require subsidies.

\subsection{Spatial models}

Spatial models are particularly relevant for modeling transportation markets, for example for the location of transportation infrastructure such as roads, railways stations, airports and seaports. In this subsection, we discuss the more common models including Hotelling, Salop and location-allocation modeling approaches.

\subsubsection{Hotelling}

In 1929, the statistician Harold Hotelling wrote about the tendency of competitors to imitate each other in quality of goods, in location, and in other essential ways in his paper 'Stability in Competition' (Hotelling, 1929). Hotelling notes that Cournot, Bertrand and Edgworth all failed to account for the location of consumers and their tendency to prefer one firm over another, today referred to as the status quo bias (Samuelson \& Zeckhauser, 1988). In order to illustrate Hotelling principles, consider a length $l$ horizontal line which could represent a linear city but for our purpose, represents a length along the coast. Two ports, $i$ and $j$, are located within $a$ unit distance from point 0 and $b$ unit distance from point $l$ respectively (see Fig. 3). The freight forwarders utilizing the service are uniformly distributed along the line $(0, l)$.

A forwarder located at point $x$ is indifferent between the two ports if:

$p_{i}+\tau(x-a)=p_{j}+\tau(l-b-x)$

where $\tau$ is the transport cost per unit distance. Solving catchment area, $x$, we find:

$x=\frac{1}{2}\left(l-b+a+\frac{p_{j}-p_{i}}{\tau}\right)$

The profit of port $i$ (and symmetrically for $j$ ) is therefore given by:

$\pi_{i}=p_{i} q_{i}=p_{i} x=\frac{1}{2}(l-b+a) p_{i}-\frac{p_{i}^{2}}{2 \tau}+\frac{p_{i} p_{j}}{2 \tau}$

Given first order conditions with respect to charges for use of the port, we find:

$p_{i}=\tau\left(l+\frac{a-b}{3}\right), \quad p_{j}=\tau\left(l-\frac{a-b}{3}\right)$

and the quantities are derived accordingly;

$q_{i}=x=\frac{1}{2}\left(l+\frac{a-b}{3}\right), \quad q_{j}=l-x=\frac{1}{2}\left(l-\frac{a-b}{3}\right)$

Hence, the profits of the ports are:

$\pi_{i}=\frac{\tau}{6}\left(l+\frac{a-b}{3}\right)^{2}, \quad \pi_{j}=\frac{\tau}{6}\left(l-\frac{a-b}{3}\right)^{2}$

To derive one of Hotelling's most interesting insights, consider a social planner who chooses the optimal location of ports $i$ and $j$ in order to minimize transportation costs for the consumers. From Fig. 3, the social planner will locate the firms at $\frac{1}{4} l$ and $\frac{3}{4} l$ such that no shipment cost exceeds $\tau \frac{1}{4} l$. However, if port $i$ 's position is fixed and port $j$ could freely choose their location, the latter will locate as close as possible to $i$, thus securing the entire market from its right and sharing the market with $i$ from the left. If both infrastructure providers are free to choose, the equilibrium outcome will be for them to co-locate in the center. According to Hotelling style competition, agglomeration of competing firms is most likely (Proost \& Thisse, 2019). However, d'Aspremont, Gabszewicz, and Thisse (1979) show that infrastructure should be located outside the quartiles for there to be an equilibrium in prices because co-location leads to the non-existence of any equilibria outcome. To correct for this, d'Aspremont et al. assume that the transportation costs are quadratic rather than linear, which is relevant where congestion exists, for example on road or railway links feeding the ports. In this setting, there is an advantage to locating at the two extremities of the coastline because the geographical separation relaxes price competition (Proost \& Thisse, 2019). 


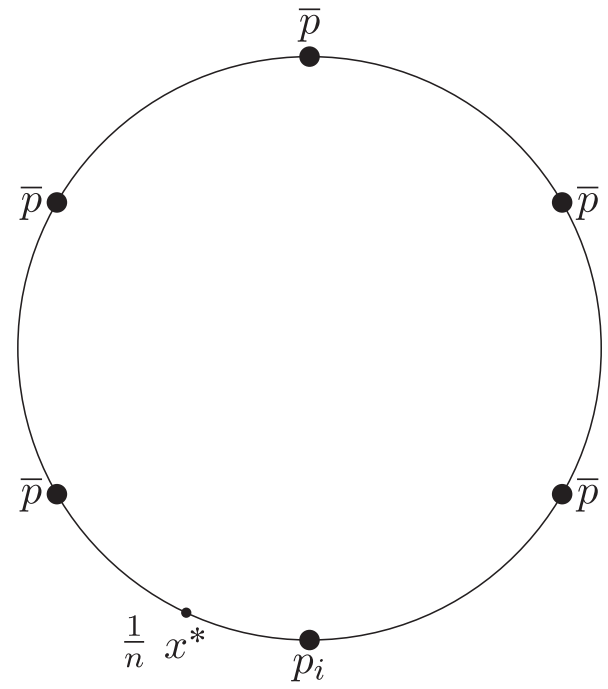

Fig. 4. Salop circular market.

\subsubsection{Salop}

A variation of Hotelling's linear model is Salop's circular model (Salop, 1979) whereby stations are located around a circle with no end-points. In the model, transport operators offer a differentiated good while a homogeneous good is offered by an outside company. Consider a circular market with $n$ operators located equidistant, $\frac{1}{n}$, from one another as shown in Fig. 4.

Assume operator $i$ is located at the bottom of the circle and offers the service at a price of $p_{i}$. In the absence of competition, $i$ attracts commuters from a maximum distance of $x$ hence the catchment area is estimated by:

$v-p_{i}-\tau x=0 \rightarrow x=\frac{v-p_{i}}{\tau}$

where $v$ is the reservation price of the commuter. If a commuter is located between two stations $\frac{1}{n}$ distance apart, denote the other station's price as $\bar{p}$, hence the catchment area of $i$ on one side is:

$v-p_{i}-\tau x=v-\bar{p}-\tau\left(\frac{1}{n}-x\right) \rightarrow x^{*}=\frac{1}{2 \tau}\left(\bar{p}+\frac{\tau}{n}-p_{i}\right)$

To assess the possible outcome of the deregulation process faced by the UK public transportation services in the late 80 's and early 90's, Evans (1987) applies the Salop spatial model to examine an optimal public transport timetable under different market structures. With the departure times corresponding to the operator's location and the schedule delay corresponding to the commuters' transportation costs, Evans concludes that competition leads to higher frequencies (transport operators offer similar timetables) and higher fares, which will result in a net loss of around 10\% in overall social welfare. Another analysis in a similar spirit is de Palma and Lindsey (2001) who determine an optimal timetable for a single bus service by minimizing schedule delay costs for passengers. They compare the Salop circle schedule where rescheduling between days is possible, to the Hotelling line scheduling where rescheduling is not possible. They conclude that ignoring the possibility of rescheduling when in fact it is applicable, may result in overestimating the schedule delay cost, hence may lead to over-investment.

\subsubsection{Location-allocation and $\mathrm{p}$-hub median models}

Location-allocation and $p$-hub median models design a network by determining the optimal location of hub or depot facilities and the allocation of customers or markets to be served by the facilities. Cooper (1963) defined the number of facilities, their locations and their capacities as decision variables given the location of the markets, the demand per market and the shipping costs. The general location-allocation problem minimizes the total cost of supplying $n$ markets with $m$ facilities:

$\min _{x_{j}, y_{j}} C=\sum_{j=1}^{j=m} \sum_{i=1}^{i=n} \alpha_{i j} c\left(x_{i}, y_{i}, x_{j}, y_{j}\right)$

where $\alpha_{i j}$ is a binary variable $=1$ if facility $j$ supplies market $i$ and $\left(x_{j}, y_{j}\right),\left(x_{i}, y_{i}\right)$ are the coordinates of the $j^{\text {th }}$ facility and $i^{\text {th }}$ location respectively. This is a combinatorial optimization problem with $2 m$ first order conditions per $\alpha_{i j}$.

Labbé and Hakimi (1991) develop a two stage, locationallocation game in which competitors determine their location in the first stage and conduct a Cournot game in the second stage. In this model there are $k$ markets, located at nodes $v_{k}$, and the transportation costs are dependent on the distance between the chosen location of firm $i$, denoted by $x_{i}$, and the market $d\left(x_{i}, v_{k}\right)$. The transport costs $\tau d\left(x_{i}, v_{k}\right)$ are dependent on $\tau$, which is the transport cost per unit distance. Each product is produced with $R$ input resources $(r=1, \ldots, R)$. Each input resource located at $y_{r}$ is provided at price $p_{r}$ and transport cost $\tau_{r}$, hence the cost to produce one unit is given by:

$c\left(x_{i}\right)=\sum_{r=1}^{R}\left[p_{r}+\tau_{r}\left(y_{r}, x_{i}\right)\right] u_{r}$

where $u_{r}$ is the number of units of resource $r$ required to produce a unit of product. The total cost of providing one unit in market $k$ is given by $c_{k}\left(x_{i}\right)=c\left(x_{i}\right)+\tau d\left(x_{i}, v_{k}\right)$ and the quantity offered to market $k$ is the sum of quantities supplied to market $k$ by both firms, $Q_{k}=q_{i k}+q_{j k}$ where $\mathbf{q}_{i}$ is the vector of quantities supplied by firm $i$ to all markets. The second stage, given the chosen locations of the two firms $x_{i}, x_{j}$, maximizes the profits accordingly:

$\max _{q_{i k}} \pi_{i}\left(x_{i}, x_{j}, \mathbf{q}_{i}, \mathbf{q}_{j}\right)=\sum_{k}\left[a_{k}-\left(q_{i k}+q_{j k}\right)-c_{k}\left(x_{i}\right)\right] q_{i k}$

and in the first stage, firm $i$ 's profit function for each location is defined as:

$\pi_{i}\left(x_{i}, x_{j}\right)=\pi_{i}\left(x_{i}, x_{j}, \mathbf{q}_{i}^{*}\left(x_{i}, x_{j}\right), \mathbf{q}_{j}^{*}\left(x_{i}, x_{j}\right)\right)$

given the optimal quantities, $\mathbf{q}^{*}$, set in the second stage. The Nash equilibrium locations in the first stage, together with the optimal quantities in the second stage, constitute a subgame perfect Nash equilibrium (Selten, 1975). Konur and Geunes (2012) model a location-allocation game and develop a heuristic method for locating multiple facilities on a congested distribution network. If we assume that the total unit costs (transportation and production costs) are lower than the consumers' reservation values such that serving the market is profitable, and that the firms locate at the vertices of the network, a subgame perfect Nash equilibrium exists, otherwise there is no guarantee.

Adler and Smilowitz (2007) develop a two stage locationallocation game with a multinomial logit market share function (see Section 3.1) in order to analyze airline competition under potential alliances or mergers. In the first stage, airlines choose their partner(s) and hub locations and in the second stage, the remaining competitors in the market participate in a Bertrand pricing game. The airline cost function is defined by the $p$-hub median problem (O'Kelly, 1987). The $p$-hub median problem can be classified into two main categories; a single allocation problem where every demand point is assigned to a single hub or multiple allocation in which every spoke may be assigned to multiple hubs (Campbell, 1994). Additional potential formulations include capacity restrictions on the hubs and on the flows between nodes (Ernst \& Krishnamoorthy, 1998). The basic $p$-hub median problem is for- 
mulated as follows (Campbell, 1996):

$\min \sum_{i} \sum_{j} \sum_{k} \sum_{m} C_{i j k m} W_{i j} X_{i j k m}$

where $X_{i j k m}$ is the allocation decision variable and represents the fraction of demand from origin $i$ to destination $j$ (denoted by $W_{i j}$ ) to be transported via hubs $k$ and $m$ at a cost of $C_{i j k m}$. The binary location decision variables, $Y_{k}$, equal 1 if location $k$ is a hub and 0 otherwise. The latter decision variables are defined in the constraints which include:
(1) $\sum_{k} Y_{k}=p$
(2) $0 \leq X_{i j k m} \leq 1 \quad \forall i, j, k, m$
(3) $\sum_{k} \sum_{m} X_{i j k m}=1 \quad \forall i, j$
(4) $X_{i j k m} \leq Y_{k} \quad \forall i, j, k, m$
(5) $X_{i j k m} \leq Y_{m} \quad \forall i, j, k, m$
(6) $Y_{k}$ binary $\forall k$

The first constraint determines that exactly $p$ hubs are chosen. Constraint (2) assigns a fraction of the flow served via hubs $k$ and $m$. Constraint (3) ensures that the flow between two spokes is served through at least one hub and Constraints (4) and (5) ensure that flows are served only via the chosen hubs.

In the $p$-hub median problem, the number of hubs, $p$, is predetermined hence ignores fixed costs. Alternatively, O'Kelly (1992) introduced a hub location problem that endogenizes the optimal number of hubs by including the fixed costs in the objective function. Alumur and Kara (2008) provide an extensive review on $p$ hub median problems and other hub location formulations which may be included within a game setting where relevant.

\subsection{Traffic assignment models}

Traffic assignment models determine paths across a transport network per user and may include physical routes, trip times or modes of transport. The models assume that each user in a network chooses the path with the lowest generalised cost from origin to destination (LeBlanc, Morlok, \& Pierskalla, 1975). In this review we discuss the Wardrop equilibrium, bottleneck model and congestion games. In many of the papers with real world applications discussed in Section 5, the games involve travelers reacting to the strategies of the transport operators or the choices of a government authority. The two stage games involving upper-level (e.g. government or transport operators) and lower level (passengers) are solved using the concept of sub-game perfect Nash equilibrium (Selten, 1975).

\subsubsection{Wardrop}

The English mathematician and transport analyst John Glen Wardrop introduced the first and second principles of equilibrium in traffic as follows (Wardrop, 1952):

1. User Equilibrium: the journey times on all the routes actually used are equal or less than those which would be experienced by a single vehicle on any unused route. Wardrop further explains that this is the likely equilibria outcome because otherwise a driver would choose a new route to reduce trip time. This principle was first identified by Knight (1924) almost three decades earlier.

2. System Optimal: the average journey time is a minimum. This principle will only occur with a central planner directing route choice or through a system of first-best optimal tolls.
These principles are frequently applied in order to evaluate the benefits of new projects, e.g. adding a lane to an existing road or implementing a toll, by estimating the redistribution of traffic across the network (Correa \& Stier-Moses, 2010). Subsequently, the static equilibrium model was mathematically formulated by Beckmann, McGuire, and Winsten (1956). The traffic assignment problem across a network of nodes $N$ and $\operatorname{arcs} A$, given by $G=$ $(N, A)$, assumes $K \subseteq N \times N$ origin-destination pairs with positive demand and for each pair $k \in K$, demand is denoted by $d_{k} . R_{k}$ is a set of routes connecting pairs $k$ and $R=\bigcup R_{k}$. For each link $a \in A$, there is a flow $f_{a}$ and a travel cost function $t_{a}\left(f_{a}\right)$. For each route $r \in R$, there is a flow $h_{r}$ such that $\sum_{r \in R_{k}} h_{r}=d_{k}$. Therefore, the flow over link $a$ is $f_{a}=\sum_{r \ni a} h_{r}$ and the travel cost along route $r$ with respect to flow $f$ ( $f$ is a vector of flows on all arcs) is $c_{r}(f)=\sum_{a \in r} t_{a}\left(f_{a}\right)$. A Wardrop Equilibrium is defined as follows:

$c_{r \in R_{k}}=\min _{q \in R_{k}} c_{q} \quad \forall k$

Beckmann et al. (1956) prove that such a flow always exists by solving the minimization problem for the total travel costs on all arcs, dependent on the separable flow on each arc as follows:

$\min _{f} T(f)=\sum_{a \in A} \int_{0}^{f_{a}} t_{a}(x) d x$

This minimum cost, multi-commodity flow function is subject to the demand constraints:

$$
\begin{aligned}
& \text { (1) } \sum_{r \in R_{k}} h_{r}=d_{k} \quad \forall k \in K \quad \text { whereby } h_{r} \geq 0 \quad \forall r \in R \\
& \text { (2) } f_{a}=\sum_{r \ni a} h_{r} \quad \forall a \in A
\end{aligned}
$$

The Wardrop equilibrium is also unique provided that the link costs are strictly increasing in the link flow (Beckmann et al., 1956). Haurie and Marcotte (1985) prove that the Cournot equilibria outcome converges to that of Wardrop when the number of infinitesimal players grows very large in a congested network, provided the payoff function is continuous and strictly quasi-concave.

The Frank-Wolfe algorithm estimates the Wardrop equilibrium as shown in LeBlanc et al. (1975). The Frank-Wolfe algorithm (Frank \& Wolfe, 1956) is an iterative process for solving a constrained convex optimization problem with linear constraints. The algorithm minimizes a linear approximation of the objective function at each iteration. Consider Eq. (2.39) and current flow $f^{i}$, the linearization of the function is $T(f) \approx T\left(f^{i}\right)+\nabla T\left(f^{i}\right)\left(f-f^{i}\right)$. The algorithm terminates when the change in the value of the objective function between two iterations is smaller than an agreed threshold. The tendency to circle around the equilibrium solution has led to performance issues hence some modifications have been published, as discussed in depth in Patriksson (2015).

\subsubsection{Bottleneck model}

The bottleneck model, first introduced by Vickrey (1969), is one of the fundamental approaches for analyzing congestion. A bottleneck occurs when the capacity of a section of a route is lower than the traffic demand, leading to delays in front of the bottleneck. Consequently, some commuters will need to either arrive late or early as compared to the uncongested circumstances. This deviation from the desired arrival time is referred to as schedule delay (Hendrickson \& Kocur, 1981).

In the bottleneck model, each commuter chooses their departure time in order to minimize their total cost, which is the sum of travel cost and schedule delay cost. Using Arnott, de Palma, and Lindsey (1994) notation, the basic model assumes $N$ identical commuters (assuming $N$ is fixed) with travel time $T(t)=T^{f}+T^{v}(t)$, where $T^{f}$ is the free flow travel time and $T^{v}(t)$ is the delay experienced at the bottleneck, given departure time $t$. Assuming $T^{f}=0$, 


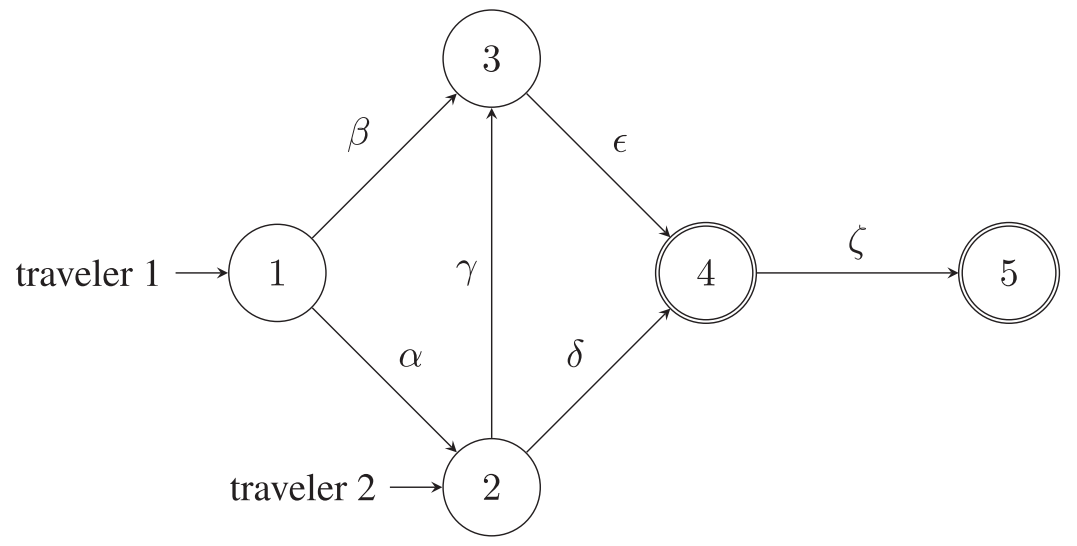

Fig. 5. An example for a congestion game.

$Q(t)$ is the number of commuters and the bottleneck has capacity $s$ at time $t$, then $T^{v}(t)=Q(t) / s$. Given the monetary value of one unit of travel time $\alpha$, arriving early time penalty $\beta$ and arriving late time penalty $\gamma$, a commuter minimizes:

$C(t)=\alpha T^{v}(t)+\beta$ (time early) $+\gamma($ time late $)+\operatorname{toll}(t)$

It is assumed that $\alpha>\beta$ in order to ensure a finite equilibrium departure rate (Arnott et al., 1994). If commuters arrive before their desired time $t^{*}$, then 'time late' equals 0 and if they arrive late, 'time early' equals 0 . Without tolls, the equilibrium outcome trades off schedule delay and travel time such that commuters minimizing schedule delay will consequently queue for longer at the bottleneck (Small, 2015).

The bottleneck model has been analyzed extensively in the road literature. Under the assumption that the number of travelers is fixed and there is only one route, a constant toll that is independent of time will not affect the equilibrium outcome or social welfare. Instead, the toll will simply transfer income from commuters to the toll operator, which may be the government or the municipality (Arnott et al., 1994). However, a time-varying toll, starting low with the first departure and increasing linearly to a peak at $t^{*}$ and then decreasing linearly until the final departure, although having no effect on schedule delays, will reduce the queue because commuters will choose when to depart as a function of the toll. In addition, social welfare increases by the amount of tolls collected (Arnott et al., 1994). One of the published applications of this model is the Stockholm congestion charge which aims at easing congestion created at the bridges leading to the city. The time-varying charge reaches its peak at the morning and afternoon rush hours, effectively eliminating the bottlenecks (Eliasson, 2008). In another well-known example, Daniel (1995) estimates tolls for Minneapolis-St. Paul airport where banking by the local hub airline creates bottlenecks at specific times of the day. Daniel arrives at the conclusion that existing airport capacity could serve about $30 \%$ more traffic under a congestion pricing regime, at the same average social cost per aircraft without the regime.

\subsubsection{Congestion games}

Congestion games are a class of non-cooperative game first proposed by Rosenthal (1973). In the context of transportation, consider traveler $i \in N=\{1, \ldots, n\}$ who has a set of strategies represented by routes $R_{i}$ and each route $r_{i} \in R_{i}$ consists of a set of links $a \in A$ (therefore $r_{i} \subseteq A$ ). The cost of choosing route $r_{i}$ is the sum of the costs of the links $c_{a}$, which is a function of $x_{a}$, the number of travelers passing over link $a$. Thus, the cost for traveler $i$ from choosing $r_{i}$ is:

$C_{i}\left(r_{1}, \ldots, r_{n}\right)=\sum_{a \in r_{i}} c_{a}\left(x_{a}\left(r_{1}, \ldots, r_{n}\right)\right)$
Table 2

Congestion game.

\begin{tabular}{llll}
\hline & & \multicolumn{2}{c}{ traveler 2 } \\
traveler 1 & $\alpha \delta$ & $\delta \zeta$ & $\gamma \epsilon \zeta$ \\
& $\beta \epsilon$ & $(4,4)$ & $(1,2)$ \\
& $\alpha \gamma \epsilon$ & $(1,1)$ & $(4,5)$ \\
& & $(2,1)$ & $(6,6)$
\end{tabular}

Equilibrium routes $r_{1}^{*}, \ldots, r_{n}^{*}$ are those satisfying $C_{i}\left(r_{1}^{*}, \ldots, r_{i}^{*}, \ldots\right.$, $\left.r_{n}^{*}\right) \leq C_{i}\left(r_{1}^{*}, \ldots, r_{i}, \ldots, r_{n}^{*}\right)$ for all travelers. An important characteristic of congestion games is that they have at least one pure strategy equilibria outcome (Rosenthal, 1973). To illustrate a congestion game, consider the example in Fig. 5 where traveler 1's origindestination pair is $(1,4)$ and traveler 2's origin-destination pair is $(2,5)$.

Traveler 1 has 3 possible route strategies; $\alpha \delta, \beta \epsilon$ and $\alpha \gamma \epsilon$. Traveler 2 has two possible route strategies; $\delta \zeta$ and $\gamma \epsilon \zeta$. Assume that the travel cost for each link as a function of the number of travelers is as follows: $c_{\alpha}\left(x_{\alpha}\right)=c_{\beta}\left(x_{\beta}\right)=c_{\zeta}\left(x_{\zeta}\right)=0, c_{\gamma}\left(x_{\gamma}\right)=x_{\gamma}$, $c_{\delta}\left(x_{\delta}\right)=x_{\delta}^{2}, \quad c_{\epsilon}\left(x_{\epsilon}\right)=x_{\epsilon}^{2}$. This game can be described as a two player, simultaneous game as shown in Table 2. There are two pure Nash equilibria: $(\beta \epsilon, \delta \zeta)$ with a cost of $(1,1)$ and $(\alpha \delta, \gamma \in \zeta)$ with a cost of $(1,2)$. There is also one solution in mixed strategies: $\left(\left(\frac{2}{3}, \frac{1}{3}, 0\right),\left(\frac{1}{2}, \frac{1}{2}\right)\right)$ with an expected cost of $\left(2 \frac{1}{2}, 3\right)$.

Congestion games are a special case of potential games, first introduced by Monderer and Shapley (1996). For a congestion game, define $R=\times_{i \in N} R_{i}$ as the set of all possible route combinations. For each combination $r \in R$ and for every link $a \in A$, the number of travelers using $a$ is given by $x_{a}(r)=\sum_{i \in N} b_{i} r_{i}$ where $b_{i}=1$ if $a \in r_{i}$ and 0 otherwise. The total cost for traveler $i$ using route $r$ is given by: $C_{i}(r)=\sum_{a \in r_{i}} c_{a}\left(x_{a}(r)\right)$ and the potential function is defined as:

$P(r)=\sum_{a \in r}\left(\sum_{x=1}^{x_{a}(r)} c_{a}(x)\right)$

$r$ is a pure strategy equilibrium if for every traveler $i: P(r) \leq$ $P\left(r^{-i}, r^{i}\right)$, for every $r^{i} \in R^{i}$. To illustrate the concept with the example, $R$ is defined as:

$R=\left\{\begin{array}{cc}(\alpha \delta, \delta \zeta) & (\alpha \delta, \gamma \epsilon \zeta) \\ (\beta \epsilon, \delta \zeta) & (\beta \epsilon, \gamma \epsilon \zeta) \\ (\alpha \gamma \epsilon, \delta \zeta) & (\alpha \gamma \epsilon, \gamma \epsilon \zeta)\end{array}\right\}$

The congestion game leads to the estimation of the number of travelers using every link per combination ( 6 combination $\times 6$ links $=36$ calculations) and the total cost for each traveler per combination. The calculations are presented in Table 3 and the last 
Table 3

\begin{tabular}{llll} 
Congestion game computations. & & \\
\hline $\begin{array}{l}\text { \# of travelers using each link } \\
\text { per route (36 eq.) }\end{array}$ & $\begin{array}{l}\text { total cost for traveler } 1 \text { per } \\
\text { route }(6 \text { eq.) }\end{array}$ & $\begin{array}{l}\text { total cost for traveler } 2 \text { per } \\
\text { route (6 eq.) }\end{array}$ & potential function for each route (6 eq.) \\
\hline$x_{\alpha}(\alpha \delta, \delta \zeta)=1$ & $C_{1}(\alpha \delta, \delta \zeta)=4$ & $C_{2}(\alpha \delta, \delta \zeta)=5$ & $P(\alpha \delta, \delta \zeta)=0+1+4+0=5$ \\
$x_{\alpha}(\alpha \delta, \gamma \epsilon \zeta)=1$ & $C_{1}(\alpha \delta, \gamma \epsilon \zeta)=1$ & $C_{2}(\alpha \delta, \gamma \epsilon \zeta)=3$ & $P(\alpha \delta, \gamma \epsilon \zeta)=0+1+1+1+0=3$ \\
$\vdots$ & $C_{1}(\beta \epsilon, \delta \zeta)=1$ & $C_{2}(\beta \epsilon, \delta \zeta)=2$ & $P(\beta \epsilon, \delta \zeta)=0+1+1+0=2$ \\
$x_{\gamma}(\alpha \gamma \epsilon, \gamma \epsilon \zeta)=2$ & $C_{1}(\beta \epsilon, \gamma \epsilon \zeta)=4$ & $C_{2}(\beta \epsilon, \gamma \epsilon \zeta)=6$ & $P(\beta \epsilon, \gamma \epsilon \zeta)=0+1+4+1+0=6$ \\
$\vdots$ & $C_{1}(\alpha \gamma \epsilon, \delta \zeta)=2$ & $C_{2}(\alpha \gamma \epsilon, \delta \zeta)=3$ & $P(\alpha \gamma \epsilon, \delta \zeta)=0+1+1+1+0=3$ \\
& $C_{1}(\alpha \gamma \epsilon, \gamma \epsilon \zeta)=6$ & $C_{2}(\alpha \gamma \epsilon, \gamma \epsilon \zeta)=8$ & $P(\alpha \gamma \epsilon, \gamma \epsilon \zeta)=0+1+2+1+4+0=8$ \\
\hline
\end{tabular}

Table 4

Potential game.

\begin{tabular}{llll}
\hline & & \multicolumn{2}{c}{ traveler 2} \\
& & $\delta \zeta$ & $\gamma \epsilon \zeta$ \\
traveler 1 & $\alpha \delta$ & 5 & 3 \\
& $\beta \epsilon$ & 2 & 6 \\
& $\alpha \gamma \epsilon$ & 3 & 8 \\
\hline
\end{tabular}

column is presented in matrix form in Table 4. Consequently, the same two equilibria outcomes: $(\beta \epsilon, \delta \zeta)$ and $(\alpha \delta, \gamma \epsilon \zeta)$ of the congestion game are also chosen in the potential game. Note here that only one of the equilibria outcomes $(\beta \epsilon, \delta \zeta)$ is also the social optimum with a minimum total cost and congestion level.

In Harks et al. (2019), a three-stage network pricing game is created in order to discuss uniform price caps on all tolled roads under government jurisdiction. The first stage models the pricecapping regulator that minimizes overall congestion, the second stage optimizes the revenues of construction firms responsible for build-operate-transfer (BOT) roads that are permitted to charge tolls and the third level models inelastic passengers minimizing the tolls and congestion costs imposed based on a Wardrop equilibrium. However, the analysis covers only two node, parallel paths and will need to be extended in order to consider a more realistic city road network. One of the important comments drawing from this paper is the argument that the Wardrop model may be problematic when applied within a multi-stage game and may lead to the non-existence of an equilibrium outcome if there is not full support, i.e. positive flows on every arc in the network. It would therefore be preferable to apply models that do not assume an uncountable continuum of users, for example using a finite potential game (Monderer \& Shapley, 1996) such as a congestion game (Rosenthal, 1973).

\subsection{Auctioning}

Auctioning is an ancient economic tool for selling goods (Milgrom et al., 1987) which introduces competition for the market in cases where competition in the market is not possible (Albalate \& Bel, 2009). Auctioning has been used to privatize transportation systems (Krishna, 2009) and towards the end of the $20^{\text {th }}$ century, has enabled the private sector to participate in the financing, building and operating of large transport infrastructure which was previously viewed as a public good to be provided by governments (Engel, Fischer, \& Galetovis, 2002). Private sector participation has increased due to the growing size of such projects, the budget constraints faced by the public sector and the belief that the private sector accomplishes the tasks more efficiently (Ubbels \& Verhoef, 2008). Literature discussing this approach covers all transport modes including road construction (De Silva, Dunne, \& Kosmopoulou, 2003), bus contracts (Ausubel et al., 2006; Tukiainen, 2008, Chapter 22), rail contracts (Borndörfer, Mura, \& Schlechte, 2009; Kuo \& Miller-Hooks, 2015; Perennes, 2014), public service obligation air routes (Pita, Adler, \& Antunes, 2014), airport slot auc- tions (Part E of Czerny, Forsyth, Gillen, \& Niemeier (2008)) and, most recently, air traffic control contracts (Adler, Hanany, \& Proost, 2020b; Ball, Donohue, \& Hoffman, 2006).

An auction is considered a game because it includes all the key ingredients. The set of players include the auctioneer (e.g. the government) that designs the auction and the bidders (e.g. private firms) that create bids, whereby the payoff equals the expected gains each player receives from the combination of strategies of all players involved. Basso and Ross (2018) distinguish between two simple and practical types of auctions used in the transportation infrastructure sector; (i) the government specifies the size of the project (quantity or capacity) and the bidders compete for compensation (prices); and (ii) the government specifies the compensation or subsidy cap (prices) for the project and the bidders compete over the size or capacity of the project to be developed (quantity). The authors name these two types "bidding the project" and "bidding the envelope" respectively and the idea draws directly from the price versus quantity regulatory mechanisms discussed in Weitzman (1974). However, auctions may involve multiple parameters, not a single price or quantity, which would require a scoring mechanism (Haurie \& Marcotte, 1985) hence an extended modeling approach.

The rapid growth in the road network has lead to multiple BOT road construction projects. The private operator builds the road, collects tolls from users for a specific period of time and then transfers the ownership of the infrastructure to the government (Chen \& Subprasom, 2007). Typically, the government determines the operating period or the level of toll and awards the franchise to the firm that either bids the lowest toll or the shortest operating period respectively. Due to the fact that demand is uncertain, under a low demand scenario there is likely to be pressure on the government to renegotiate the agreement. Engel, Fischer, and Galetovic (2001) introduce an alternative criteria entitled 'least present value of revenue' in which the government announces the level of the toll and the discount rate. The firms then bid on the net present value of the toll revenues whereby the project is transferred once sufficient revenues have been collected. The lowest bid wins the auction under this system and the risk sharing mechanism reduces the likelihood of renegotiation at a later date. This mechanism has since been implemented in transport infrastructure projects in Chile (Basso \& Ross, 2018). Verhoef (2007) analyzes the optimal winning criterion for a road with an untolled alternative road or an untolled consecutive road, concluding that under the assumption of constant returns to scale, maximizing traffic flow leads to a second best outcome. Ubbels and Verhoef (2008) analyze evaluation criteria in the bidding process considering an untolled alternative and permitting subsidies. They conclude that the auction design could lead to widely varying results where capacity maximization or subsidy minimization are less useful metrics. The minimization of generalized travel costs plus subsidy divided by demand is more likely to achieve the social surplus objective. However, applying such a criteria requires an assumption that the value of time is known and that the travelers are homogeneous with respect to their value of time. 
Bus services have also been privatized and undergone auctioning processes in many countries. In 1984, the city of London began a competitive tendering scheme over three year contracts and reportedly achieved substantial savings (Kennedy, 1995). On the other hand, a side effect of this iterative process is a consolidation of companies through mergers and cross-ownership which erodes the savings in the longer term (Hensher \& Wallis, 2005; Mathisen \& Solvoll, 2008).

However, apart from a recent study that analyzes the introduction of competition to air traffic control in Western Europe through auctioning by Adler et al. (2020b), to the best of our knowledge, an application to a real-world case is missing from the literature. There are many papers however which give a descriptive analysis of auctions and tendering from the real world, such as the London bus system reform in 1984 (Amaral, Saussier, \& Yvrande-Billon, 2009; Banister, Berechman, \& De Rus, 1992; Kennedy, 1995).

\section{Consumer behavior, demand modeling and social welfare analysis}

One of the key elements in transport models is the demand for the transportation services. From a game-theoretic perspective, passenger demand responds to the supply of service or the tolls set by infrastructure providers or a government body. The simplest models assume that demand for a transport alternative, whether freight shipper, route choice or mode selection, is dependent on a single variable, namely price or travel time. Yet, demand is frequently dependent on several attributes such as a combination of travel time, price, convenience and frequency of service etc. The preferable choice may also be dependent on the characteristics of the travelers themselves, for example income, education and gender etc. In this section, we discuss several modeling approaches that improve demand forecasting by assuming that traveler preferences may be formulated as a utility function (Horowitz, 1980). The utility function within a discrete choice approach includes both deterministic and random components, with the latter accounting for the effects of unobserved characteristics. Discrete choice approaches may also consider mixed strategies when the choices are executed with probabilities. To define the utility function, consider a traveler $i$ who faces $r \in R$ alternatives as follows:

$U_{i r}=V_{i r}+\varepsilon_{i r}$

where $V_{i r}$ is the observed utility for traveler $i$ choosing alternative $r$ and $\varepsilon_{i r}$ is the independent and identically distributed unknown in the utility function. $V_{i r}$ is often based on a linear representation of all the characteristics considered relevant by the researcher and for which data is available:

$V_{\text {ir }}=\boldsymbol{\beta}^{\prime} \mathbf{x}_{\text {ir }}$

where $\mathbf{x}_{i r}$ is a vector of of observed characteristics for alternative $r$ and $\beta$ is the vector of coefficients representing the relative weight or importance of each characteristic. The models subsequently assume that travelers choose the alternative that maximizes their utility (McFadden, 1973). If we consider only two alternatives and the difference between the unobserved terms $\left(\varepsilon_{i}=\varepsilon_{i 2}-\varepsilon_{i 1}\right)$ is uniformly distributed between two values ( $-L$ and $L$ ), the probability of choosing the first alternative is:

$\operatorname{Prob}_{i 1}=\operatorname{Prob}\left(V_{i 1}+\varepsilon_{i 1} \geq V_{i 2}+\varepsilon_{i 2}\right)=\operatorname{Prob}\left(\varepsilon_{i} \leq V_{i 1}-V_{i 2}\right)$

Since $V_{i 1}$ and $V_{i 2}$ are linear in the parameters, $\operatorname{Prob}_{i 1}$ is a linear function lying between the two values $-L$ and $L$ (Ben-Akiva, Lerman, \& Lerman, 1985).

\subsection{Logit}

The assumption of a linear probability function is frequently considered unrealistic, hence alternative models have been

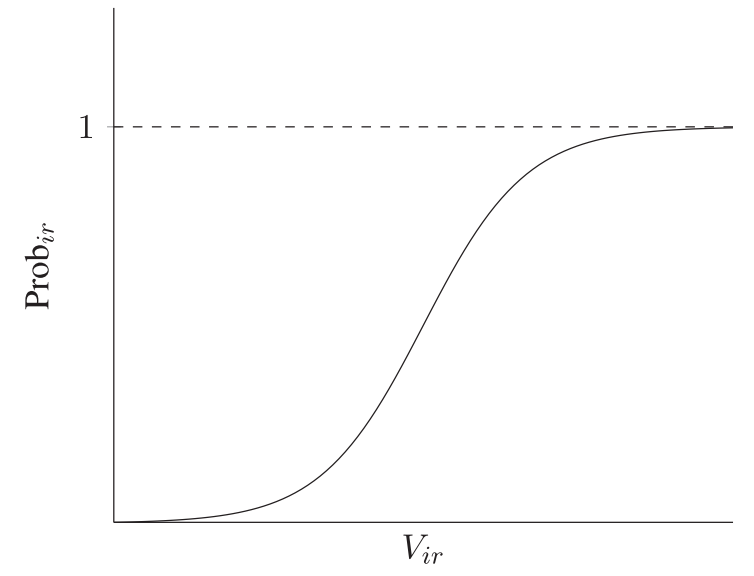

Fig. 6. The logit function curve.

published in the literature in order to improve real-world analyses. One of the more popular discrete choice models is the multinomial logit, formalized by McFadden (1973). In order to employ a discrete choice model, the choice set must meet two requirements: (i) the set of alternatives must be collectively exhaustive and finite; and (ii) the alternatives must be mutually exclusive. The probability of traveler $i$ choosing alternative $r$ within a multinomial logit function is defined as:

$\operatorname{Prob}_{i r}=\frac{e^{V_{i r}}}{\sum_{r^{\prime} \in R} e^{V_{i r^{\prime}}}}$

and plotting this function leads to the s-shaped curve in Fig. 6 .

One of the properties of the multinomial logit model is the independent and identically distributed (IID) error terms which imply that the alternatives have no common, unobserved components that may affect their utilities. This assumption is violated, for example, if a traveler assigns a common component (e.g. environmental soundness) to all transit modes (Koppelman \& Bhat, 2006). A more general discrete choice model is the multinomial probit model which, contrary to the logit function, allows the unobserved variables to be correlated across alternatives hence may be applicable to a broader range of cases (Horowitz, 1980). The second multinomial logit property is the independence of irrelevant alternatives (IIA) which states that the ratio of probabilities between two alternatives is irrelevant of other alternatives. In other words, if $y$ is strictly preferred to $x$ then a choice set of $(x, y, z)$ in which $z$ is not a preferred option should always lead to the choice of $y$. This assumption may pose limitations particularly in the case of similar alternatives i.e. close substitutes. McFadden (1973) demonstrates this issue with an example which came to be known as the red bus-blue bus example. If the initial choice is between a car and a red bus and the commuter chooses a mode with equal probability, after adding a third alternative, namely the blue bus, the market share between the two modes should not change (assuming commuters do not attribute value to the color of the bus). However, under the standard logit model, each of the three alternatives would receive an equivalent probability of being chosen. To overcome the issue of substitutability, Ben-Akiva (1973) developed and McFadden (1978) formalised a nested (or hierarchical) logit function. Sets of alternatives are grouped into sub-sets, or nests, and the IIA property holds within each nest but not across nests (Train, 2009). Under nested logit, the probability of traveler $i$ choosing alternative $r$ which belongs to nest $m \in M$ is defined as (Koppelman \& Wen, 1998):

$\operatorname{Prob}_{i r}=\operatorname{Prob}_{i r \mid i m} \times \operatorname{Prob}_{i m}$ 
where

Prob $_{i r \mid i m}=\frac{e^{V_{i r} \mid \mu_{m}}}{\sum_{r^{\prime} \in R_{m}} e^{V_{i r^{\prime}} \mid \mu_{m}}}$

and

$\operatorname{Prob}_{i m}=\frac{e^{\mu_{m} \ln \sum_{r^{\prime} \in R_{m}} e^{V_{i r^{\prime}}}}}{\sum_{m^{\prime} \in M} e^{\mu_{m^{\prime}} \ln \sum_{r^{\prime} \in R_{m^{\prime}}} e^{V_{i r^{\prime}}}}}$

$\mu_{m}$ is a parameter representing the diversity in nest $m$ and $R_{m}$ are the alternatives belonging to nest $m$. Note that if $\mu_{m}=1$, the model collapses back to the standard multinomial logit.

Many of the applications described in Section 5 utilise either logit or nested logit. For example, Adler et al. (2010) describes an imperfectly substitutable high speed rail and airline market using a two nested logit function with airlines in one nest and the rail and road options in a separate nest. The demand functions are then utilized within a market share model that connects the demand and supply side of the model. Provided the transport operators' decision variables impact both demand and supply, the best response objective function balances revenues and costs within a competitive perspective.

\subsection{Social welfare}

Much of the literature on transportation systems concerns the maximization of overall social welfare which in a game-theoretic analysis includes the aggregate welfare of all actors, including operators' profits and travelers' surplus. The latter is often a more complicated concept to estimate as it measures the difference in the value of the service to the traveler and the generalized costs. In a linear demand function, traveler surplus is the area above the equilibrium price and below the demand curve as depicted by the shaded area in Fig. 2. Small and Rosen (1981) provide a detailed methodology for estimating social welfare within a discrete choice demand model and De Jong, Daly, Pieters, and Van der Hoorn (2007) extends the discussion. They describe the 'logsum' as a measure of consumer surplus which estimates the expected utility of consumer $i$ over all alternatives:

$E\left(C S_{i}\right)=\frac{1}{\alpha_{i}} \ln \left(\sum_{r^{\prime} \in R} e^{V_{i r^{\prime}}}\right)$

where $\alpha_{i}$ is the marginal utility of income of traveler $i$. It should be noted that the estimation of consumer surplus is accurate up to plus/minus a constant value. As such, it may be applied to evaluate the contribution of infrastructure projects and replace other classic measures. De Jong et al. (2007) illustrate the applicability of the approach by analyzing a planned high speed rail project in The Netherlands. Additional elements of the social welfare function may include government surplus, consisting of taxes collected and subsidies paid, and externalities such as mobility, accessibility, wider economic benefits, pollution or congestion. Examples of social welfare formulations and estimations are found in Adler et al. (2010), Zou and Hansen (2012) and D'Alfonso, Jiang, and Bracaglia (2015), as discussed in Section 5.

\section{Alternative solution methodologies}

Several approaches have been developed to solve gametheoretic models in general and transport models in particular. Algorithms to solve game-theoretic models draw from all the classic optimization techniques developed within the operational research literature. The single-stage game with best response, non-linear but convex objective functions and linear constraints are solvable to optimality under Karush-Kuhn-Tucker conditions (Bazaraa, Sherali, \& Shetty, 2013). The non-linear best response functions that include congestion or logit demand functions for example, are frequently solved with steepest descent algorithms such as Frank and Wolfe (1956). Location-allocation p-hub median problems are frequently solved in the academic literature using mixed integer linear programming (MILP). However, for real-world problem sizes, heuristic approaches are required which trade off time constraints and an optimality gap (Campbell, 1994; Ernst \& Krishnamoorthy, 1998). Many heuristic approaches have been adopted to solve large network optimizations, which are relevant for game-theoretic formulations too, including shortest paths (Ernst \& Krishnamoorthy, 1998), variable neighborhood search (Ilić, Urošević, Brimberg, \& Mladenović, 2010), genetic algorithms (Asadabadi \& MillerHooks, 2017; Yamada, Russ, Castro, \& Taniguchi, 2009), tabu search (Crainic, Gendreau, \& Farvolden, 2000; Sun, Aronson, McKeown, \& Drinka, 1998), simulated annealing (Jayaraman \& Ross, 2003), column generation (Desrochers \& Soumis, 1989), large neighbourhood search (Ropke \& Pisinger, 2006) and hybrid meta heuristics (Poorzahedy \& Rouhani, 2007) among others.

One of the standard approaches to solve a game has been defined variously as best response mapping, best reply dynamics, myopic best response and fictitious play. The approach solves the game iteratively such that the model is solved for a specific player, assuming that all other players' decisions remain constant, and the search continues until no player deviates from their choice set over two successive rounds of the game (Garcia, Reaume, \& Smith, 2000; Monderer \& Shapley, 1996). In a two-stage game, first stage player $i$ 's problem is analyzed and then all second stage players are solved iteratively until an equilibrium is found, after which player $i$ is revisited and the computations continue until player $i$ no longer changes the value of the decision variables over two consecutive iterations. Subsequently, the algorithm moves to first stage player $i+1$ 's problem and repeats the process. A round is completed after all first-stage players have been analyzed. A subgame perfect Nash equilibria outcome is deemed to have been found after two successive rounds in which the players in both stages have not deviated by changing the value of their decision variables (Selten, 1975). We note that, in general, the existence of a pure strategy Nash equilibria cannot be guaranteed (mixed strategy outcomes are guaranteed (Nash et al., 1950)) and if found, uniqueness is not necessarily ensured without additional restrictions. Conditions that would guarantee pure strategy Nash equilibria include (i) a compact and convex strategy space together with (ii) a continuous and quasi-concave payoff function (Debreu, 1952). Furthermore, Rosenthal (1973) was able to show that congestion games possess a pure-strategy equilibrium. Substantial further details on this topic can be found in Cachon and Netessine (2006).

Additional methods for reformulating the models in order to solve the games efficiently include variational inequalities (Hartman, Stampacchia et al., 1966) and bilevel programming (Bialas \& Karwan, 1984; Candler \& Townsley, 1982) which are discussed next.

\subsection{Variational inequalities}

Variational inequalities provide a general mathematical form which is applied to solve optimization problems and define the conditions under which an equilibrium exists and whether it is unique (Harker \& Pang, 1990). Referring back to Eq. (1.1), if $S_{i}$ is nonempty, closed and convex, $S=\prod_{i \in N} S_{i}$ and $u_{i}$ is once continuously differentiable and pseudo-concave with respect to $s_{i}$ for all $i$, then $s^{*} \in S$ is a solution to the Nash equilibrium problem if and only if $s^{*} \in S$ is a solution to the following variational inequality:

$\sum_{i \in N} F_{i}\left(s^{*}\right)^{\top}\left(s_{i}-s_{i}^{*}\right) \geq 0 \quad \forall s \in S$ 
where $F_{i}(s)=-\nabla_{s_{i}} u_{i}(s)$ is the negative partial derivative vector of the utility function. For example, referring back to Eq. (2.39), the variational inequality form of the Wardrop equilibrium states that $f^{*}$ is an equilibrium for all feasible $f$ (Van Vliet, 1987) if:

$\sum_{a \in A} c_{a}\left(f^{*}\right)\left(f_{a}-f_{a}^{*}\right) \geq 0$

Variational inequality formulations have been applied to many transport models, for example Dafermos (1980) applied the ideas to the transport equilibrium, Marcotte (1985) to the traffic assignment model, Nagurney and Ramanujam (1996) to transport network pricing and extensive surveys of finite-dimensional variational inequalities can be found in Harker and Pang (1990) and Giannessi and Maugeri (1995). Fernandez and Marcotte (1992) use variational inequalities to solve a Cournot game representing a partially deregulated bus system for which the fare structure is determined exogenously and the bus operators optimize their routes and frequencies whilst accounting for congestion on the road network caused by commuters.

\subsection{Bilevel programming}

Bilevel programs have been applied to Stackelberg games in which a major transport operator with large market share chooses service levels first and a follower responds accordingly. Many papers alternatively refer to a regulator setting for example tolls in the first stage and the follower subsequently choosing a path that minimizes generalized costs. The leader or upper bilevel linear program is of the form (Vicente \& Calamai, 1994):

$$
\min _{x, y} F(x, y)
$$

subject to $g(x, y) \leq 0$

where $y$, for each value of $x$, is a solution to the follower, or lower level optimization problem assuming a feasible solution exists:

$$
\min _{y} f(x, y)
$$

subject to $h(x, y) \leq 0$

Labbé, Marcotte, and Savard (1998) develop a Stackelberg game with an infrastructure manager setting tolls on multi-commodity transportation network arcs with the objective of maximizing profits. The follower chooses their path by minimizing a generalized cost function composed of a cumulative, monetarized trip time and travel costs. The authors solve a linear bilevel programming formulation in order to derive an optimal solution. Although the authors show that the linear-linear bilevel program is strongly NP-hard, special cases of the problem are solved in polynomial time, for example as a mixed integer program with a small number of binary variables. Bilevel programs have been further extended to the continuous transport network design problem in Chiou (2005) and the optimal capacity and toll problem in Xu, Wang, Grant-Muller, and Gao (2017).

The main issues drawing from the bilinear formulation are twofold. First is the assumption that there is a single player in each stage which is not reasonable in most transport markets. By replacing the second stage transport operators with, for example bus timetables or flight frequencies, ignores the market power potentially available in the oligopolistic market which in turn may lead to an inaccurate assessment of the likely equilibria outcomes. Second is the fact that should there be multiple equilibria in the second-stage of the game, then the equilibrium outcome is chosen in the best interests of the first stage player. This may be reasonable if the first stage player has bargaining power over the follower, otherwise it would be better to search for the multiple sub-game perfect Nash equilibria outcomes.
Extensions to the single player assumption have been extensive in both the transportation and electricity market literature. The lower level of the bilevel game may involve several operators competing in a market and the equilibrium state is then applied as a parameter in the upper level problem. The resulting Mathematical Program with Equilibrium Constraints is known as MPEC. In the case of multiple leaders and multiple followers, an Equilibrium Problem with Equilibrium Constraints is known as EPEC (Che-Lin, 2005). These are referred to as dynamic games of complete and imperfect information in the gametheoretic literature (Kuhn, 1950). Koh (2012) formulated a game between several private, profit maximizing, toll operators who act as leaders and second stage commuters who choose their routes according to the Wardrop Equilibrium. The sub-game perfect Nash equilibrium is solved using an evolutionary algorithmic approach. Asadabadi and Miller-Hooks (2017) solve a bilevel formulation whereby authorities choose an investment strategy over a road network subject to the potential threat of sea level rising and storms affecting the network at the upper level and drivers choose their routes in the case of such events at the lower level. The two-stage, stochastic, mixed-integer program is solved using a recursive noisy genetic algorithm. However, both MPEC and EPEC formulations suffer from the same drawbacks as the bilevel approach, hence may fail to find all equilibrium outcomes.

\section{Real-world transportation applications}

In this section, we review papers published to date that contain real-world applications with a game-theoretic component. The first such paper probably dates back to Littlechild and Thompson (1977), however the majority have been published since the turn of the century. One of the major challenges in applying gametheoretic network models to analyze private or public policy decisions has been the calibration process (Adler, Fu, Oum, \& Yu, 2014). The usual approach is to choose parameters within the range of previous empirical estimates. Whilst such an approach may be reasonable when the aim of the research is to demonstrate the theoretical application through an illustration, this would seem more problematic when analyzing specific markets and policies. Furthermore, even if studies do exist, it is often difficult to borrow key parameters directly unless precisely the same assumptions have been applied to the same types of transport operators. Finally, modelers often compare market equilibria with and without the implementation of certain policies by forecasting market outcomes prior to undertaking policy scenario evaluations. As a result, data observed from the current market cannot be applied directly for scenario construction or econometric estimation. One method to address these challenges may be the counter-factual approach which analyzes what would have been the outcome were such policies introduced during an observable period in the past, thus based directly on current industry data. Furthermore, counter-factuals may help to validate the parameters by first reproducing the observed market equilibrium. In Doyme, Dray, O'Sullivan, and Schäfer (2019), a serious effort is made to reproduce the Australian aviation market equilibrium outcome using an $n$-player non-cooperative game. The authors estimate fares, frequencies, passenger numbers and market shares across the four domestic players hence validating the argument that the game-theoretic models are able to estimate real-world outcomes in transportation markets. In this section, we discuss the individual transport modes and a few multi-modal comparisons. For a brief summary of the modeling approaches and their application to real-world cases published in the literature, see Table 5. 
Table 5

Modeling approaches and their transportation applications.

\begin{tabular}{ll}
\hline Modeling approaches & Cases in literature \\
\hline Cournot & Port competition between Antwerp and Rotterdam (Kaselimi et al., 2011) \\
Bertrand & Port competition between Korea and China (Anderson et al., 2008) \\
& Multi-modal competition in Cologne-Berlin corridor (Ivaldi \& Vibes, 2008) \\
& Air-HSR competition in Europe (Adler et al., 2010) \\
& Air-HSR competition in China (Yang \& Zhang, 2012) \\
& Multi-modal competition in Madrid-Baecelona corridor (Ruiz-Rúa \& Palacín, 2013) \\
& Air-HSR competition in the North East Asia (Adler et al., 2014) \\
& Parking policy in Central London (Calthrop \& Proost, 2006) \\
Stackelberg & Port competition between Korea and Japan (Ishii et al., 2013) \\
& Dynamic parking pricing and reservation at Uni. of Illinois (Lei \& Ouyang, 2017) \\
& Air-HSR competition in China (Yang \& Zhang, 2012) \\
Hotelling & Airline competition in Amsterdam-Maastricht corridor (Schipper et al., 2007) \\
Salop & Airline competition in the South-Atlantic market (Martín \& Román, 2003) \\
Location-allocation & Parking policy in Zurich (van Nieuwkoop et al., 2016) \\
Wardrop & Airport congestion at Minneapolis-St. Paul airport (Daniel, 1995) \\
Bottleneck & Air traffic control competition in Western Europe (Adler et al., 2020a; 2020b) \\
Congestion games & Air traffic control competition in Western Europe (Adler et al., 2020b) \\
Auctioning &
\end{tabular}

\subsection{Road literature}

The road literature is replete with discussions of road pricing, however very few include a real-world application that estimates the likely impact and social welfare implications. Road pricing is usually under the control of governments and the impact of tolls may be difficult to estimate in a simple pay-off function. De Borger and Proost (2016) assess the likely behavior of two regional governments setting congestion prices and fares in their own region and show that local residents gain at the expense of tax visitors from the other regions. Mandell and Proost (2016) use a similar model to explain the proliferation of distance charging on international trucking across Europe.

In Engevall, Göthe-Lundgren, and Värbrand (2004), a vehicle routing game is modeled in order to determine the allocation of transportation costs between customers. The cooperative $n$-person cost game is first tested to see whether a core exists and then the authors develop a procedure to estimate the Shapley value and the nucleolus, thus minimizing maximal dissatisfaction amongst customers. In the case of Norsk Hydro gas deliveries, the authors show that the Shapley value allocates more of the costs to the customers with low demand and lower costs to the customers with substantial demand compared to that of the nucleolus solution. In Sherali and Lunday (2011), equitable allocations of railcars are analyzed for the TTX Reload Group which acts as a central agency connecting nine carriers and 17 shippers within the US. The conclusions suggest that the Shapley value provides an equitable basis for allocation but should be adapted in order to account for both capital and operating costs within the pooling agreement.

Stackelberg models have been used to explore urban parking policies, for example Calthrop and Proost (2006) define the government as the leader, intent on maximizing welfare by setting the price for on-street parking that also includes the cost of searching for a limited number of spaces. The commercial, off-street operator is defined as the follower, and sets prices in order to maximize profits. Solving the model for Central London highlights the simple policy measure that sets the price for on-street parking to match that of the off-street parking thus maximizing welfare. Furthermore, a simple time restriction, in which the driver pays no charge as long as parking is less than a given length of time, is welfare inferior to an optimal meter fee due to the excessive search costs. Consequently, pricing is a more useful regulatory tool in this case compared to quantity levers (Weitzman, 1974). Lei and Ouyang (2017) explore a dynamic pricing and parking reservation mechanism for parking lots. They formulate a Stackelberg game where the parking agency sets prices and the commuters choose where to park, leading to a demand distribution. The bilevel, multiperiod mathematical program with equilibrium constraints (MPEC) is solved using dynamic programming and produces a set of prices as a function of the occupancy levels.

van Nieuwkoop, Axhausen, and Rutherford (2016) apply a Wardrop model in order to analyze the welfare and distributional effect of parking policies for the case of Zurich, Switzerland. They find that the the current parking policy in the city is inefficient but potential new efficiency-inducing policies may be regressive. Yet to be analyzed with real-world applications using game-theoretic tools are (i) workplace parking prices which are likely to impact employees' mode choice (Brueckner \& Franco, 2018; Dowling, Feltham, \& Wycko, 1991; Higgins, 1992; Willson \& Shoup, 1990); and (ii) pricing of residential parking (Brueckner \& Franco, 2016; Weinberger, 2012).

\subsection{Rail literature}

In the rail literature, several papers have analyzed competition between high speed rail (HSR) and alternative transport modes, including standard rail, bus and airlines, dependent on the distances analyzed. Game theory could be applied as part of a benefit-cost analysis in order to estimate a priori the value of the construction of new railway infrastructure which would impact competition in the market and would help to set suitable subsidy levels where necessary.

Adler et al. (2010) develop a framework in order to assess imperfectly substitutable transport networks in the medium to long distance passenger market. Given HSR infrastructure and pricing, a game-theoretic framework analyzes competition between HSR and airlines, including low cost and network carriers. Three profit maximizing transport operators are defined and compete for passengers through a nested logit function that takes into account total trip time, fares and frequencies. A second-stage social welfare function generates an objective analysis of the equilibria outcomes across multiple HSR scenarios all of which are a function of the decisions of the transports operators. The social welfare function aggregates transport operators profits, passenger surplus, infrastructure manager surplus and government surplus, which accounts for externalities such as the environment (Small \& Rosen, 1981). The case study covers 27 European Union countries and models six transport operators whilst highlighting the potential impact of four Trans-European Network HSR projects on the transport equilibria outcome. The substantial cost of the four projects, in the region 
of 85 billion euros (in 2010 values), suggests that an analysis of this type that directly models the competitive reactions of private transport companies, accounting for schedule quality and price endogenously, could contribute to a comprehensive cost-benefit analysis. The main conclusions are (i) HSR market share decreases in distance, attracting $25 \%$ at 750 kilometers and dropping to $9 \%$ in the longer haul markets; (ii) the HSR operator is unlikely to cover the full cost of the infrastructure because fares would be high hence the service levels would be inefficiently low; (iii) negative externalities are higher when the rail access charge is relatively high because of a modal shift to air; and (iv) negative externalities are slightly higher with the Trans-European Network because the external cost of HSR exceeds that of standard rail and the low cost carriers increase frequency to better compete with the improved rail competitor. Consequently, a policy with the intention of stimulating a modal shift from aviation to rail for environmental reasons would require on-track HSR competition, price regulation and/or substantial environmental taxes.

Yang and Zhang (2012) create an adapted Hotelling-Bertrand model in order to capture product differentiation. Airlines, assumed to be profit maximizers, compete in the market with HSR operators that are assumed to maximize a weighted sum of welfare and profit, due to their public ownership form. For a $600 \mathrm{~km}$ corridor in China, the authors find that as the welfare weights increase (i) the HSR ticket prices and airfares decrease; (ii) flight frequency decreases whereas HSR frequency increases; and (iii) flight and HSR frequencies increase as the relative share of business passengers increases.

Adler et al. (2014) further develop the multi-mode, differentiated Bertrand network game to consider additional issues such as the impact of the Maglev, slot allocation and open skies policies on future transport equilibria in North East Asia. The underlying analysis in this research is a counter-factual approach in which the existing equilibria outcome is reproduced and potential changes are examined through what-if analysis. The framework involves a number of regulators that set the rules of the market thus creating scenarios and a set of transport operators maximizing profit bestresponse functions in a single-stage differentiated Bertrand game. Multiple passenger types are modeled indirectly via a market share model based on a nested logit function (Hensher, Rose, \& Greene, 2005). The case study covers China, Japan and Korea, namely North East Asia, which are divided into 60 zones and 10 transport operators are modeled in the game. General conclusions include (i) liberalization benefits both passengers and airlines in the Northeast Asian region, albeit to varying degrees; (ii) much of the welfare gains are derived from higher frequency after liberalization, which increases service quality hence passenger utility; (iii) the airport slot allocation system has significant spill-over effects; and (iv) the Maglev's enhanced speed and quality could overwhelm airline service in short to medium haul routes.

Talebian and Zou (2016) argue that train technology is an important element of HSR and airline market competition, hence model this issue directly. They develop a three-stage, gametheoretic model such that the rail agency first chooses track technology hence the accompanying speed, in the second stage rail and airline frequencies are chosen and in the last stage, each mode determines their fares. The authors analyze four mid-west US markets and find that (i) conventional rail could not compete with air in any of the markets; (ii) HSR competes with aviation and attracts market share from the routes in addition to inducing new markets; (iii) if the rail company was publicly owned, the HSR alternative would become the dominant mode; and (iv) the shorter the rail station egress and access times, the higher the market share for rail. Raturi and Verma (2019) model competition in two corridors in India, with the shorter line analyzing HSR and bus competition and the longer line analyzing HSR and an airline. A three- stage entry game considers the HSR entrant's choice of speed, in the second stage the alternative mode sets fares and frequencies and in the third stage, HSR chooses whether to enter the market and if yes, the best response fares and frequencies. The passengers are modeled through a logit, market share model (McFadden, 1973) based on revealed and stated preference surveys of the two markets. Their results suggest that the optimal choice of HSR speed will depend on the specific market characteristics hence should be incorporated into such modeling approaches.

\subsection{Port literature}

Lee and Song (2017) review the literature on ocean container transport in global supply chains. They describe both competitive and cooperative game-theoretic models that have been developed over the last decade in order to analyze port competition, particularly in the container shipping industry. However, they also state that many of the papers to date are somewhat simplistic, failing to consider important elements likely to be relevant in these markets.

Anderson et al. (2008) develop a game to analyze competition between two East Asian ports, namely Busan, Korea and Shanghai, China. The two-stage, Bertrand outcome defines the payoffs of the two ports as a function of capacity investment in the first stage and price setting competition in the second stage. The capacity scenarios include faster turnaround times, additional equipment or new terminals. The authors argue that the expected increase in market share and revenues drawing from additional investments appear to be relatively marginal hence such investments should be carefully considered. Otherwise, a surplus of port capacity could push prices towards marginal costs at all ports, which may in turn lead to an inability to recover investments.

Saeed and Larsen (2010) develop a two-stage game in which the management of intra-port container terminals choose whether to join a coalition and in a second stage, the coalition competes with non-coalitional partners and inter-port competitors by setting Bertrand prices. They apply a coalitional game with transferable utilities utilizing the core concept to the three Karachi port terminals. They find that the grand coalition is the only equilibria outcome which will lead to high prices and dissatisfied shippers. Ishii et al. (2013) develop a multi-period, two stage, Stackelberg game in which each port sequentially sets capacities and subsequently maximizes expected profits as a function of first-stage capacities and second-stage port charges given stochastic demand. This style of analysis explains the development of Busan and Kobe ports which were of a similar size in 1994 but by 2008, whilst Kobe retained similar throughput, Busan had expanded by a magnitude of seven.

Kaselimi et al. (2011) study the container-handling intra-port and inter-port competition through differentiated Cournot competition.The differentiation is location dependent, hence a Hotelling model estimates the total cost to the shippers. They also explore the effect of a dedicated terminal that handles a specific customer or strategic alliance, on the competition between the remaining terminals. They base their numerical example on the competition between Antwerp and Rotterdam in the Rhine-Scheldt Delta for the year 2007. They conclude that the port operators will not be substantially affected by the dedicated terminal conversion, however the cost to the shippers is likely to rise and congestion at the other terminals will increase.

In the port integration literature, Dong, Zheng, and Lee (2018) develop a three-stage game whereby adjacent ports first decide whether to integrate, then each decides on the level of effort invested in integration and finally each maximizes their individual container throughput. The application to the Ningo and Zhoushan ports in China suggest that integration may improve efficiency by reducing handling charges and increasing container 
throughput up to a certain demand level at which point, decreasing economies of scale may become an issue. Asadabadi and Miller-Hooks (2018) study the coopetition strategies of ports investing in capacity expansion as a protective measure against disasters. They develop a bilevel model, initially as an MPEC with a single port, followed by an EPEC, in which the ports choose the level of protective investments necessary to mitigate the effects of a disaster in the first stage and shipping companies choose their network by minimizing total handling costs in the second stage. They apply the model to ports in East Asia and Europe and find that a coopetition may support higher capacities and reduce overall shipping costs.

\subsection{Aviation literature}

In the aviation literature, games have been developed in order to analyze airport charges, develop optimal airline networks, assess the likely impact of liberalization and evaluate subsidy policies necessary to protect thin markets in the era of deregulation. We have already mentioned Daniel (1995)'s application of the bottleneck model to estimate congestion tolls for Minneapolis-St. Paul airport and one of the first papers to apply a game-theoretic model in which cooperative concepts are applied to estimate airport charges at Birmingham airport (Littlechild \& Thompson, 1977). In Doyme et al. (2019), the authors apply an $n$-player non-cooperative game to the Australian domestic four-airline market using a gravity model to estimate demand and a multinomial logit function to estimate market shares. In order to solve the game, the authors linearize the non-linear objective function and non-linear market share constraint which requires a strong starting point in order to ensure the subsequent computations approximate the existing equilibria outcome. By comparing the transport equilibria in 2014 to that predicted by the model, the results suggest that the modeling approach accurately predicts frequencies, passenger flows, air fares and market shares.

Martín and Román (2003) published one of the first papers to analyze hub location choices through a spatial competition game played in two stages. In the first stage, airlines choose their hub locations sequentially and in a second-stage, they compete by offering direct or connecting services between city-pairs. The inelastic market share model is based on a logit function and the deterministic utility is based on the circuity of service, the highest and lowest frequencies offered over the legs of the trip and a pre-set airfare (Hansen, 1990). The airlines' choices are thus the hub chosen among a set of potential locations in the first stage and frequencies in the second stage. The authors analyze the South-American - European market, known as South-Atlantic, in anticipation of the signing of an open skies agreements between all countries. The results suggest that five two-hub locations are the most likely, covering Madrid, Lisbon and Sao Paolo.

Adler (2005) develops a framework for analyzing hub-spoke network design whilst taking into account competing networks. The model combines a market share model together with a CobbDouglas cost function in a two-stage game whereby airlines choose their hub-spoke network in the first stage and aircraft sizes, frequencies and fares per passenger type in the second stage in order to maximize their profit best response functions. The passengers are taken into account indirectly through the logit function and their utility is dependent on passenger type and the frequencies and airfares chosen by the airlines. A relatively simple application to Western Europe analyses three two-hub airline networks and finds that (i) for sufficient demand, only two of the three airlines will achieve positive profits; (ii) under duopolistic conditions, each airline removes connections to the competitor's hub connections in order to avoid competing aggressively; and (iii) airfares are relatively similar, once again enabling the airlines not to compete aggressively. The modeling approach was extended in Adler and Smilowitz (2007) in order to assess the impact of alliances on the likely choice of hubs in the North-Atlantic market. The modeling approach connects the $p$-hub median problem (Campbell, 1996; O'Kelly, 1987) within a game-theoretic framework. The non-cooperative, two-stage game determines the partners and their network configuration in the first stage and airfares in the second stage. After analyzing a four airline game with two carriers located on each of the continents, the research suggests that (i) several equilibria outcomes are possible leading to three players remaining in the market and the choice of international gateway will depend on the carriers remaining; (ii) average airfares are lower after the alliance, suggesting that behind and beyond travelers are better off; and (iii) the results are robust to changes in the hub-to-hub discount factor utilised in the $p$-median hub problem.

Schipper et al. (2007) model airline competition following a spatial, Salop, oligopolistic approach in which airlines first set frequencies and then airfares, in line with the timing of such decisions. The model is applied to the Amsterdam-Maastricht corridor. The authors find asymmetric subgame perfect equilibria outcomes due to either a differing cost structure between the two airlines and/or varying consumer loyalties towards a specific airline. The equilibrium outcome suggests that both low cost carriers and network incumbent airlines could serve the corridor, which is in the interest of consumer welfare too.

Vaze and Barnhart (2012) model airline frequency competition in order to shed light on congestion issues and slot constraints at major hubs. Airlines maximize profits by setting frequencies given average fares and deterministic demand. The best response dynamics function converges within a few iterations irrespective of the starting point. The authors show that the model predictions match frequencies reasonably well after analyzing the LaGuardia airport market in New York. In an extension of the game to a two-stage frequency and price analysis considering 11 airports and four airlines covering the Western US, Vaze and Harder (2012) argue that such a behavioural model could be utilized as a planning, forecasting and policy decision support tool.

In Adler and Hanany (2016), a coopetition approach is employed in order to compare aviation markets under conditions of competition, codesharing contracts and anti-trust immune alliances (Brandenburger \& Nalebuff, 1996). The airline decision process is defined as a two-stage setting in which, facing uncertain demand, airlines choose whether to sign codeshare agreements and set frequencies in the first stage and, after the uncertainty clears, set airfares in a second stage. The analysis is based on two-stage Nash equilibrium and Nash bargaining solutions (Nash, 1950), which are estimated for each agreement type. The analysis of three Israeli gateway-to-gateway routes highlights the following: (i) the most common inter-governmental agreements, known as bi-laterals, are consistently the worst of all possibilities, drastically reducing frequencies and increasing airfares; (ii) the stronger the inter-airline agreement on overlapping routes, the higher the producer surplus; (iii) whilst leisure passengers in markets with sufficient demand prefer the no agreement outcome, business passengers prefer competitive or bilateral codeshares hence overall passenger surplus is maximized under codeshares; (iv) under thin market conditions with low demand and profit levels, any form of inter-airline agreement increases passenger surplus beyond that of the competitive equilibrium outcome; and (v) under asymmetric and uncertain demand, codesharing on parallel links may be preferable to competitive outcomes for both types of passengers.

In the air traffic control literature, several papers have attempted to shed light on the last link of the aviation market to be liberalized. In Castelli, Labbé, and Violin (2013), a route charge pricing problem is introduced whereby in the first stage an air 
traffic control (ATC) provider sets a charge and in the second stage, flight paths are chosen so as to minimize costs, including the ATC charges. The problem is defined in the form of a bilevel program and solved for Switzerland, suggesting that revenue maximizing, non-price capped ATC agencies would increase their prices. In Adler, Hanany, and Proost (2020a), a two-stage, network congestion game models multiple ATC providers in the first stage and multiple airlines in the second stage, assuming the potential for market power in both stages. Consequently, this style of analysis will result in different results to those of the route charge pricing problem. The first stage ATC providers set user charges according to revenue or profit maximization and the airlines subsequently choose their flight paths in order to minimize labour, fuel, congestion and ATC costs, all of which are impacted to some degree by the ATC provision. Conclusions drawn from the analysis of Western Europe suggest that: (i) there is insufficient competition between ATC providers in order to justify the removal of economic pricecap regulation; (ii) price caps in congested networks are ineffective due to their failure to signal the existence of scarce resources; (iii) horizontal integration between ATC providers may improve efficiency; and (iv) vertical integration may prove beneficial by incentivising the providers to expand capacity through technology adoption although this is dependent on the pricing regime. In Adler et al. (2020b), the authors further develop the model by introducing an auction enabling the ATC providers to bid to serve a specific airspace. The first stage ATC firms maximize profits by setting labour levels, technology and user charges and the airlines subsequently choose their flight paths to minimize their direct operating costs. The conclusions drawn from the analysis of six countries in Western Europe suggest that (i) defragmentation of the European skies is likely to occur under this scenario as ATC companies win more than one auction; (ii) an on-going auction system will reduce existing ATC charges substantially; and (iii) new technologies are more likely to be adopted where deemed necessary to meet the key performance indices set by each Member State within the tender guidelines.

\subsection{Multi-modal literature}

In Ivaldi and Vibes (2008), a Bertrand model is developed with a nested logit demand function defining the market share between multiple modes serving a corridor. The $600 \mathrm{~km}$ Cologne-Berlin corridor is served by rail, road and air options. After reproducing the existing Nash equilibria outcome, the authors include an additional low-cost rail service, assuming that the new service will achieve half the marginal cost of the existing Deutsche Bahn service. Prices drop by $30 \%$, especially in the leisure passenger market with substantial impact on the low cost carrier market share. Thus the paper concludes that on-rail competition is viable and highly beneficial to passengers in this relatively dense transport market. In Ruiz-Rúa and Palacín (2013), a two stage game determines in the first stage whether the transport operators intend to participate and their investment strategy and in the second stage Bertrand competition sets fares. The $500 \mathrm{~km}$ Madrid-Barcelona corridor is analyzed with two rail companies and an alternative mode of transport.

Of interest today is the potential for creating mixed-mode trips and game-theoretic models which consider coopetition both on corridors and across networks (Brandenburger \& Nalebuff, 1996). For example, García-Albertos et al. (2016) found that $44 \%$ of traffic in the Barcelona-Madrid corridor use the car mode and of the remainder, rail captures a similar level, leaving air with less than $15 \%$. If authorities are interested in encouraging passengers to choose alternative modes compared to the private vehicle in order to minimize accidents, congestion and pollution, it is necessary to think about multi-modal trips between regions rather than the simple corridor approach currently considered. A starting point for thinking about the multi-modal market within an urban setting can be found in Roumboutsos and Kapros (2008). The authors identify strategies such as integrated fares, common station interconnections and routing, scheduling and information provision as the important elements of a functional multi-modal market.

\section{Insights and future research paths}

This paper has reviewed the application of game-theoretic concepts and the associated computational techniques of relevance when modeling transportation markets. The literature now offers a wide diversity of case studies covering all modes of transport and it has become obvious that there is no universally valid model relevant to all transport markets. The steps required to build a gametheoretic analysis begin with the definition of relevant players, their decision variables (i.e. possible strategies) and resultant objective function (i.e. payoffs). It is important to choose the network, players and decision variables judiciously because of the need to balance the size of the problem to ensure computational tractability with the need to capture the main operators in the market. This is crucial and tends to be ignored by models that focus on pure minimization of complex operational or logistics costs. If the market is regulated, it is worthwhile considering whether to endogenize the role of the regulator by creating multiple stages of the game because this is often preferable to scenario analysis.

The second step is to describe the dynamics of the market, for example, is capacity fixed or expandable, and if the latter, within what time frame? Is there a technological game-changer such as autonomous vehicles or micro-transport modes that may shift the demand from public transport or complement it?

The third step is to choose the modeling approach and this is to some extent determined by the set of decision variables chosen. In many applications, the transport operator chooses the prices, fares or charges, in which case Bertrand would be the appropriate modeling choice. Of course, under the pure Bertrand model, no operator would achieve profits so, if this does not describe the existing market, then quality of the service offered would need to be endogenised leading to a differentiated Bertrand analysis. Frequencies, connecting times and choice of network, such as railway stations or airports, could all help to differentiate services. If the transport operators have similar market power and control quantities, then Cournot might be the reasonable choice. If the market is defined by two operators whereby one serves the majority of the market share, then Stackelberg may be relevant. For example, Stackelberg has been widely used to model hubbing airlines that set high frequency and airfare in a hub-destination market and a second airline follows, generally with lower frequency and airfare. If you are interested in modeling both longer term and shorter term decisions, such as network capacities and prices, then a two-stage model would be necessary. Under certain conditions, this two stage approach is equivalent to a single-stage Cournot game (Kreps \& Scheinkman, 1983). However, one of the conditions assumes that production follows the realization of demand which is less relevant to timetabled transport markets. If there is a location question, it may be possible to embed the location-allocation or traffic assignment decisions inside a multi-stage game that allows you to also account for competitors' reactions to the operator's choice of location. Furthermore, when embedding the demand side interactions into the game, it is always worthwhile starting with a simple linear function unless quality is of importance and preferences need to be taken into account. Heterogeniety of customers requires an extended analysis if this is likely to impact the type and amount of services offered. For example, a railway service may need to differentiate fares between commuters and passengers with other trip purposes in order to better handle the rush 
hour peak. Fu, van den Berg, and Verhoef (2018) analyze road pricing and highlight the importance of accounting for the heterogeneity of travellers because a tolled express lane may be welfare improving provided there is sufficient differentiation in the value of time. In aviation markets, business passengers place importance on minimising schedule delay whereas leisure passengers place greater importance on airfare. Airlines that attempted to serve a homogeneous passenger type generally failed to survive (Adler \& Gellman, 2012). Models that account for both passenger types in the market share function will lead to improved schedules compared to those based on the average passenger.

The fourth step is the careful calibration of the underlying parameters, potentially by reproducing the current equilibria outcome. The usual approach to choosing parameters is to pick a value within the range of previous empirical estimates. However, crossing continents and markets is somewhat problematic when deriving policy initiatives relevant to a country or operational analyses for a specific company. Furthermore, modelers often compare market equilibria with and without the implementation of specific policies by forecasting market outcomes prior to undertaking policy scenario evaluations which is a two step procedure that may lead to biases and inaccurate predictions. One method to address these challenges may be the counter-factual approach which analyzes what would have been the outcome were such policies introduced during an observable period in the past, thus based on observable industry data directly, creating a conservative what-if style of analysis.

Finally, there is the computational challenge of solving the models because the equilibrium is the result of the interaction of several interdependent optimization problems that may also cause externalities, whether negative (congestion, pollution) or positive (mobility, accessibility and equity). Whenever there is a multiplicity of equilibria, one also needs to consider the choice between all potential equilibria outcomes.

Despite all these stumbling blocks, real world applications are blossoming due to advances in operational research methods and exploding data availability. We see five future research paths that have yet to be explored in depth.

\subsection{The long and winding road towards equilibrium}

For many of the models discussed and solved, equilibrium have been shown to exist, yet the path to the equilibrium is rarely discussed in the transport literature. The assumption appears to be that some kind of hidden mechanism lying behind travel behavior leads to equilibrium (Cominetti, Melo, \& Sorin, 2010). Nevertheless, the basis to understand the path to equilibrium does exist in the more theoretical literature of games. One framework for understanding the process of convergence towards the equilibrium is the "learning from experience" procedure in repeated games (Fudenberg \& Levine, 1998) which may be relevant to cases of bounded rationality too (Kalai \& Lehrer, 1993). Experimental data suggests that we may expect slower convergence when players are less informed (Roth \& Erev, 1995) and it is unclear whether this phenomenon is relevant to transports markets, but may be particularly pertinent in multi-modal trips. We found three papers that discuss the issue of convergence. Cominetti et al. (2010) applied the leaning process to study convergence to Wardrop equilibria. Wie (1993) applied a differential game to investigate the convergence to Wardrop's second principal. Finally, Wang, Fan, Zhao, and Wu (2015) used an evolutionary game to study policies aimed at encouraging auto manufacturers to shift to clean energy vehicles.

\subsection{Creating evidence based regulatory policies}

The second research path is the need to carefully create more realistic representations of the pay-off functions of the operators in the market. A particularly difficult point is how to define the behavior of a government which generally needs to balance the needs of multiple stakeholders in the transport market and encourage efficient outcomes. Government surplus is often defined as a simple summation of passenger surplus and transport operator profits which may be a rather poor representation of the behaviour of an elected government (Besley, 2006). The governments set the rules of the game but are often also important players in the market hence their role and decision variables should be included directly in the analysis, possibly in a first stage of the game. Subsequently, the concept of time needs to be carefully considered, as discussed in the next paragraph.

\subsection{Modeling dynamic transport markets}

A third important avenue is to consider carefully whether a static representation is sufficient or whether a dynamic approach might be more representative. Many of the games described in this paper and applied to real-world cases are of the static or one-shot variety. Static equilibria are be viewed as steady states of recurring plays of a game (Rubinstein \& Wolinsky, 1994) and have shown predictive power even in repeated settings (Kruse, 1993; Kruse, Rassenti, Reynolds, \& Smith, 1994). If the static game has a unique equilibria outcome then the result would be the same as that of a dynamic, finite horizon game. The advantage of a repeated game analysis is that it allows the parties to threaten to play alternative strategies in the following time period should the collusive equilibria agreement be voided. However, it is unclear how realistic this assumption may be as cartels are difficult to control and the larger the number of players, the more difficult this would be to maintain. Consequently, collusive equilibria in dynamic games, assuming infinite time horizons, are preferable when modeling a market with very few competitors. Timing is also of relevance when analyzing longer term and expensive capacity decisions as compared to shorter term timetables and pricing. This style of analysis has yet to be tested, in particular with reference to benefit-cost analysis of transport infrastructure projects.

\subsection{Multi-modal trip analysis through coopetition}

The fourth research path involves the need to develop modeling approaches in order to analyze markets composed of multi-modal trips, in other words considering door-to-door trips where travelers combine multiple modes across an origin-destination pair. As urbanization continues, the need to generate policies that encourage the use of public transit, whether fixed or on-demand, and ensure access to the first and last mile is being discussed all over the world. Operational research models, in combination with economic underpinnings, could help to search for appropriate policies specific to a region or urban center. A few papers are just beginning to consider these issues, such as Scheltes and de Almeida Correia (2017) and Shen, Zhang, and Zhao (2018) but obviously this is just the beginning.

\subsection{Modeling the autonomous vehicle market}

The fifth and final research path concerns the impact of the autonomous vehicle revolution that may begin this decade. Autonomous vehicle technologies have been extensively discussed in the computer science and engineering literature since the early 1990's, however the operational research and economics literature have yet to tackle the issues from a policy perspective. Many of the existing OR models, such as the dial-a-ride problem, vehicle routing problem and signal control problem, could be applicable to this new market but will require adaptations. It is likely that the positive externalities will outweigh the negatives, but only if the mar- 
ket is carefully managed and the technology is adopted. Fagnant and Kockelman (2015) have started the conversation, arguing that autonomous vehicles represent a potentially disruptive technology that will reduce accidents and improve mobility for under-served populations. On the other hand, the potential increase in vehicle miles traveled due to induced traffic may have additional unintended effects such as further urban sprawl (Milakis, Kroesen, \& van Wee, 2018). The application of the modeling approaches discussed in this review have yet to be applied to this new and exciting market.

\section{Acknowledgements}

We would like to thank the participants of EURO 2019 and the 1 st SOAR meeting for useful comments and especially the two reviewers of a previous version of this paper for helpful comments. Nicole Adler would like to thank the Recanati Foundation for partial funding of this research.

\section{References}

Adler, N. (2001). Competition in a deregulated air transportation market. European Journal of Operational Research, 129(2), 337-345

Adler, N. (2005). Hub-spoke network choice under competition with an application to western europe. Transportation Science, 39(1), 58-72.

Adler, N., Fu, X., Oum, T. H., \& Yu, C. (2014). Air transport liberalization and airport slot allocation: The case of the northeast asian transport market. Transportation Research Part A: Policy and Practice, 62, 3-19.

Adler, N., \& Gellman, A. (2012). Strategies for managing risk in a changing aviation environment. Journal of air transport management, 21, 24-35.

Adler, N., \& Hanany, E. (2016). Regulating inter-firm agreements: The case of airline codesharing in parallel networks. Transportation Research Part B: Methodological, $84,31-54$

Adler, N., Hanany, E., \& Proost, S. (2020a). Competition in congested service networks with application to air traffic control provision in Europe. Working Paper, The Hebrew University of Jerusalem.

Adler, N., Hanany, E., \& Proost, S. (2020b). Introducing competition through auctions in the air traffic control market. Working Paper. The Hebrew University of Jerusalem.

Adler, N., Pels, E., \& Nash, C. (2010). High-speed rail and air transport competition: Game engineering as tool for cost-benefit analysis. Transportation Research Part B: Methodological, 44(7), 812-833.

Adler, N., \& Smilowitz, K. (2007). Hub-and-spoke network alliances and mergers: Price-location competition in the airline industry. Transportation Research Part B: Methodological, 41(4), 394-409.

Albalate, D., \& Bel, G. (2009). Regulating concessions of toll motorways: An empirical study on fixed vs. variable term contracts. Transportation Research Part A: Policy and Practice, 43(2), 219-229.

Algaba, E., Fragnelli, V., Llorca, N., \& Sánchez-Soriano, J. (2019). Horizontal cooperation in a multimodal public transport system: The profit allocation problem. European Journal of Operational Research, 275(2), 659-665.

Alumur, S., \& Kara, B. Y. (2008). Network hub location problems: The state of the art. European journal of operational research, 190(1), 1-21.

Amaral, M., Saussier, S., \& Yvrande-Billon, A. (2009). Auction procedures and competition in public services: The case of urban public transport in France and London. Utilities policy, 17(2), 166-175.

Anderson, C. M., Park, Y.-A., Chang, Y.-T., Yang, C.-H., Lee, T.-W., \& Luo, M. (2008). A game-theoretic analysis of competition among container port hubs: the case of busan and shanghai. Maritime Policy \& Management, 35(1), 5-26.

Arnott, R., de Palma, A., \& Lindsey, R. (1994). The welfare effects of congestion tolls with heterogeneous commuters. Journal of Transport Economics and Policy, 139-161.

Arrow, K. J. (1963). Social choice and individual values. Yale University Press.

Asadabadi, A., \& Miller-Hooks, E. (2017). Optimal transportation and shoreline infrastructure investment planning under a stochastic climate future. Transportation Research Part B: Methodological, 100, 156-174.

Asadabadi, A., \& Miller-Hooks, E. (2018). Co-opetition in enhancing global port network resiliency: A multi-leader, common-follower game theoretic approach. Transportation Research Part B: Methodological, 108, 281-298.

Aumann, R. J., \& Shapley, L. S. (1994). Long-term competition-a game-theoretic analysis. In Essays in game theory (pp. 1-15). Springer.

Ausubel, L., Cramton, P., Milgrom, P., Cramton, P., Shoham, Y., \& Steinberg, R. (2006). Combinatorial auctions.

Ball, M., Donohue, G., \& Hoffman, K. (2006). Auctions for the safe, efficient, and equitable allocation of airspace system resources. Combinatorial Auctions, 1.

Banister, D., Berechman, J., \& De Rus, G. (1992). Competitive regimes within the European bus industry: Theory and practice. Transportation Research Part A: Policy and Practice, 26(2), 167-178.

Basso, L. J., \& Ross, T. W. (2018). "bidding the project" vs."bidding the envelope" in public sector infrastructure procurements. Transport Policy, 64, 61-75.
Bazaraa, M. S., Sherali, H. D., \& Shetty, C. M. (2013). Nonlinear programming: Theory and algorithms. John Wiley \& Sons.

Beckmann, M., McGuire, C., \& Winsten, C. (1956). Studies in the economics of transportation. Cowles Commission for Research in Economics.

Bell, M. G. (1999). Measuring network reliability: A game theoretic approach. Journal of advanced transportation, 33(2), 135-146.

Bell, M. G., \& Cassir, C. (2002). Risk-averse user equilibrium traffic assignment: An application of game theory. Transportation Research Part B: Methodological, 36(8), 671-681.

Ben-Akiva, M. E. (1973). Structure of passenger travel demand models.. Massachusetts Institute of Technology Ph.D. thesis..

Ben-Akiva, M. E., Lerman, S. R., \& Lerman, S. R. (1985). Discrete choice analysis: theory and application to travel demand: 9. MIT press.

Bertrand, J. (1883). Book review of theorie mathematique de la richesse social and of recherches sur les principes mathematiques de la theorie des richesses. Journal des Savants.

Besley, T. (2006). Principled agents?: The political economy of good government. Oxford University Press on Demand.

Bialas, W. F., \& Karwan, M. H. (1984). Two-level linear programming. Management science, 30(8), 1004-1020.

Borenstein, S. (1989). Hubs and high fares: dominance and market power in the us airline industry. The RAND Journal of Economics, 344-365.

Borenstein, S. (1992). The evolution of us airline competition. Journal of Economic perspectives, 6(2), 45-73.

Borndörfer, R., Mura, A., \& Schlechte, T. (2009). Vickrey auctions for railway tracks. In Operations research proceedings 2008 (pp. 551-556). Springer.

Brandenburger, A., \& Nalebuff, B. J. (1996). Coopetition, currency doubleday. New York,.

Brander, J. A., \& Zhang, A. (1990). Market conduct in the airline industry: an empirical investigation. The RAND Journal of Economics, 567-583.

Brueckner, J. K., \& Franco, S. F. (2016). Parking and urban form. Journal of Economic Geography, 17(1), 95-127.

Brueckner, J. K., \& Franco, S. F. (2018). Employer-paid parking, mode choice, and suburbanization. Journal of Urban Economics, 104, 35-46.

Cachon, G. P., \& Netessine, S. (2006). Game theory in supply chain analysis. In Models, methods, and applications for innovative decision making (pp. 200-233). INFORMS.

Calthrop, E. \& Proost, S. (2006). Regulating on-street parking. Regional Science and Urban Economics, 36(1), 29-48.

Campbell, J. F. (1994). Integer programming formulations of discrete hub location problems. European Journal of Operational Research, 72(2), 387-405.

Campbell, J. F. (1996). Hub location and the p-hub median problem. Operations research, 44(6), 923-935.

Candler, W., \& Townsley, R. (1982). A linear two-level programming problem. Computers \& Operations Research, 9(1), 59-76.

Castelli, L., Labbé, M., \& Violin, A. (2013). A network pricing formulation for the revenue maximization of European air navigation service providers. Transportation Research Part C: Emerging Technologies, 33, 214-226.

Caves, R. W. (2005). Encyclopedia of the city. Taylor \& Francis.

Che-Lin, S. (2005). Equilibrium problems with equilibrium constraints: Stationarities algorithms and applications Ph. D. dissertation.

Chen, A., \& Subprasom, K. (2007). Analysis of regulation and policy of private toll roads in a build-operate-transfer scheme under demand uncertainty. Transportation Research Part A: Policy and Practice, 41(6), 537-558.

Chiou, S.-W. (2005). Bilevel programming for the continuous transport network design problem. Transportation Research Part B: Methodological, 39(4), 361-383.

Cominetti, R., Melo, E., \& Sorin, S. (2010). A payoff-based learning procedure and its application to traffic games. Games and Economic Behavior, 70(1), 71-83.

Cooper, L. (1963). Location-allocation problems. Operations research, 11(3), 331-343.

Correa, J. R., \& Stier-Moses, N. E. (2010). Wardrop equilibria. Wiley Encyclopedia of Operations Research and Management Science.

Cournot, A. A. (1838). Recherches sur les principes mathématiques de la théorie des richesses.

Crainic, T. G., Gendreau, M., \& Farvolden, J. M. (2000). A simplex-based tabu search method for capacitated network design. INFORMS Journal on Computing, 12(3), 223-236.

Czerny, A. I., Forsyth, P., Gillen, D., \& Niemeier, H.-M. (2008). Airport slots: international experiences and options for reform. Ashgate Publishing, Ltd.

Dafermos, S. (1980). Traffic equilibrium and variational inequalities. Transportation Science, 14(1), 42-54.

Daniel, J. I. (1995). Congestion pricing and capacity of large hub airports: A bottleneck model with stochastic queues. Econometrica: Journal of the Econometric Society, 327-370.

d'Aspremont, C., Gabszewicz, J. J., \& Thisse, J.-F. (1979). On hotelling's" stability in competition". Econometrica: Journal of the Econometric Society, 1145-1150.

De Borger, B., \& Proost, S. (2016). Can we leave road pricing to the regions?-the role of institutional constraints. Regional Science and Urban Economics, 60, 208-222.

De Jong, G., Daly, A., Pieters, M., \& Van der Hoorn, T. (2007). The logsum as an evaluation measure: Review of the literature and new results. Transportation Research Part A: Policy and Practice, 41(9), 874-889.

de Palma, A., \& Leruth, L. (1989). Congestion and game in capacity: a duopoly analysis in the presence of network externalities. Annales d'Economie et de Statistique, 389-407.

de Palma, A., \& Lindsey, R. (2001). Optimal timetables for public transportation. Transportation Research Part B: Methodological, 35(8), 789-813. 
De Silva, D. G., Dunne, T., \& Kosmopoulou, G. (2003). An empirical analysis of entrant and incumbent bidding in road construction auctions. The Journal of Industrial Economics, 51(3), 295-316.

Debreu, G. (1952). A social equilibrium existence theorem. Proceedings of the National Academy of Sciences, 38(10), 886-893.

Desrochers, M., \& Soumis, F. (1989). A column generation approach to the urban transit crew scheduling problem. Transportation science, 23(1), 1-13.

Dong, G., Zheng, S., \& Lee, P. T.-W. (2018). The effects of regional port integration: The case of Ningbo-Zhoushan port. Transportation Research Part E: Logistics and Transportation Review, 120, 1-15.

Dowling, R., Feltham, D., \& Wycko, W. (1991). Factors affecting transportation demand management program effectiveness at six san francisco medical institutions. Transportation Research Record, 1321, 109-117.

Doyme, K., Dray, L., O’Sullivan, A., \& Schäfer, A. (2019). Simulating airline behavior: Application for the australian domestic market. Transportation Research Record, 2673(2), 104-112.

D’Alfonso, T. Jiang, C. \& Bracaglia, V. (2015). Would competition between air transport and high-speed rail benefit environment and social welfare? Transportation Research Part B: Methodological, 74, 118-137.

Edgeworth, F. (1889). The pure theory of monopoly, reprinted in collected papers relating to political economy 1925 , vol. 1.

Edgeworth, F. Y. (1881). Mathematical psychics: An essay on the application of mathematics to the moral sciences: 10. Kegan Paul.

Eliasson, J. (2008). Lessons from the stockholm congestion charging trial. Transport Policy, 15(6), 395-404.

Engel, E., Fischer, R., \& Galetovis, A. (2002). A new approach to private roads. Regulation, 25, 18

Engel, E. M., Fischer, R. D., \& Galetovic, A. (2001). Least-present-value-of-revenue auctions and highway franchising. Journal of Political Economy, 109(5), 993-1020.

Engevall, S., Göthe-Lundgren, M., \& Värbrand, P. (2004). The heterogeneous vehicle-routing game. Transportation Science, 38(1), 71-85.

Ernst, A. T., \& Krishnamoorthy, M. (1998). Exact and heuristic algorithms for the uncapacitated multiple allocation p-hub median problem. European Journal of Operational Research, 104(1), 100-112.

Evans, A. (1987). A theoretical comparison of competition with other economic regimes for bus services. Journal of Transport Economics and Policy, 7-36.

Fagnant, D. J., \& Kockelman, K. (2015). Preparing a nation for autonomous vehicles: opportunities, barriers and policy recommendations. Transportation Research Part A: Policy and Practice, 77, 167-181.

Fernandez, E., \& Marcotte, P. (1992). Operators-users equilibrium model in a partially regulated transit system. Transportation Science, 26(2), 93-105.

Fisk, C. (1984). Game theory and transportation systems modelling. Transportation Research Part B: Methodological, 18(4-5), 301-313.

Frank, M., \& Wolfe, P. (1956). An algorithm for quadratic programming. Naval Research Logistics Quarterly, 3(1-2), 95-110.

Frisk, M., Göthe-Lundgren, M., Jörnsten, K., \& Rönnqvist, M. (2010). Cost allocation in collaborative forest transportation. European Journal of Operational Research, 205(2), 448-458.

Fu, X., van den Berg, V. A., \& Verhoef, E. T. (2018). Private road supply in networks with heterogeneous users. Transportation Research Part A: Policy and Practice, 118, 430-443.

Fudenberg, D. \& Levine, D. K. (1998). The theory of learning in games: 2.

Garcia, A., Reaume, D., \& Smith, R. L. (2000). Fictitious play for finding system optimal routings in dynamic traffic networks. Transportation Research Part B: Methodological, 34(2), 147-156.

García-Albertos, P., Herranz, R., Ramasco, J., Andrienko, G., Adler, N., \& Ciruelos, C. (2016). Big data analytics for a passenger-centric air traffic management system. SESAR Innovation Days.

Giannessi, F., \& Maugeri, A. (1995). Variational inequalities and network equilibrium problems. Springer.

Gibbons, R. S. (1992). Game theory for applied economists. Princeton University Press.

Gillies, D. (1953). Some theorems on n-person games. Princeton University, Department of Mathematics Ph. D. Dissertation.

Hansen, M. (1990). Airline competition in a hub-dominated environment: An application of noncooperative game theory. Transportation Research Part B: Methodological, 24(1), 27-43.

Harker, P. T., \& Pang, J.-S. (1990). Finite-dimensional variational inequality and nonlinear complementarity problems: A survey of theory, algorithms and applications. Mathematical Programming, 48(1-3), 161-220.

Harks, T., Schröder, M., \& Vermeulen, D. (2019). Toll caps in privatized road networks. European Journal of Operational Research, 276(3), 947-956.

Hart, S. (1989). Shapley value. In Game theory (pp. 210-216). Springer.

Hartman, P., Stampacchia, G., et al. (1966). On some non-linear elliptic differentialfunctional equations. Acta Mathematica, 115, 271-310.

Haurie, A., \& Marcotte, P. (1985). On the relationship between Nash-Cournot and Wardrop equilibria. Networks, 15(3), 295-308.

Hendrickson, C., \& Kocur, G. (1981). Schedule delay and departure time decisions in a deterministic model. Transportation Science, 15(1), 62-77.

Hensher, D. A., Rose, J. M., \& Greene, W. H. (2005). Applied choice analysis: a primer. Cambridge University Press.

Hensher, D. A., \& Wallis, I. P. (2005). Competitive tendering as a contracting mechanism for subsidising transport: the bus experience. Journal of Transport Economics and Policy (JTEP), 39(3), 295-322.

Higgins, T. J. (1992). Parking taxes: effectiveness, legality and implementation, some general considerations. Transportation, 19(3), 221-230.
Hollander, Y., \& Prashker, J. N. (2006). The applicability of non-cooperative game theory in transport analysis. Transportation, 33(5), 481-496.

Horowitz, J. (1980). The accuracy of the multinomial logit model as an approximation to the multinomial probit model of travel demand. Transportation Research Part B: Methodological, 14(4), 331-341.

Hotelling, H. (1929). Stability in competition. The Economic Journal, 39(153), 41-57.

Ilić, A., Urošević, D., Brimberg, J., \& Mladenović, N. (2010). A general variable neighborhood search for solving the uncapacitated single allocation p-hub median problem. European Journal of Operational Research, 206(2), 289-300.

Ishii, M., Lee, P. T.-W., Tezuka, K., \& Chang, Y.-T. (2013). A game theoretical analysis of port competition. Transportation Research Part E: Logistics and Transportation Review, 49(1), 92-106.

Ivaldi, M., \& Vibes, C. (2008). Price competition in the intercity passenger transport market: a simulation model. Journal of Transport Economics and Policy (JTEP), 42(2), 225-254.

Jayaraman, V., \& Ross, A. (2003). A simulated annealing methodology to distribution network design and management. European Journal of Operational Research, 144(3), 629-645.

Jørgensen, F., \& Mathisen, T. A. (2014). Market equilibriums for transport operators with several goals. European Transport Research Review, 6(3), 241-251.

Kalai, E., \& Lehrer, E. (1993). Rational learning leads to Nash equilibrium. Econometrica: Journal of the Econometric Society, 1019-1045.

Kannai, Y. (1992). The core and balancedness. Handbook of Game Theory With Economic Applications, 1, 355-395.

Kaselimi, E. N., Notteboom, T. E., \& De Borger, B. (2011). A game theoretical approach to competition between multi-user terminals: The impact of dedicated terminals. Maritime Policy \& Management, 38(4), 395-414.

Kennedy, D. (1995). London bus tendering: A welfare balance. Transport Policy, 2(4), 243-249.

Knight, F. H. (1924). Some fallacies in the interpretation of social cost. The Quarterly Journal of Economics, 38(4), 582-606.

Koh, A. (2012). An evolutionary algorithm based on Nash dominance for equilibrium problems with equilibrium constraints. Applied Soft Computing, 12(1), 161-173.

Konur, D., \& Geunes, J. (2012). Competitive multi-facility location games with non-identical firms and convex traffic congestion costs. Transportation Research Part E: Logistics and Transportation Review, 48(1), 373-385.

Koppelman, F. S., \& Bhat, C. (2006). A self instructing course in mode choice modeling: Multinomial and nested logit models.

Koppelman, F. S., \& Wen, C.-H. (1998). Alternative nested logit models: structure, properties and estimation. Transportation Research Part B: Methodological, 32(5), 289-298.

Koutsoupias, E., \& Papadimitriou, C. (1999). Worst-case equilibria. In Annual symposium on theoretical aspects of computer science (pp. 404-413). Springer.

Kreps, D. M., \& Scheinkman, J. A. (1983). Quantity precommitment and bertrand competition yield Cournot outcomes. The Bell Journal of Economics, 326-337.

Krishna, V. (2009). Auction theory. Academic press.

Kruse, J. B. (1993). Nash equilibrium and buyer rationing rules: experimental evidence. Economic Inquiry, 31(4), 631-646.

Kruse, J. B., Rassenti, S., Reynolds, S. S., \& Smith, V. L. (1994). Bertrand-Edgeworth competition in experimental markets. Econometrica: Journal of the Econometric Society, 343-371.

Kuhn, H. W. (1950). Extensive games. Proceedings of the National Academy of Sciences of the United States of America, 36(10), 570.

Kuo, A., \& Miller-Hooks, E. (2015). Combinatorial auctions of railway track capacity in vertically separated freight transport markets. Journal of Rail Transport Planning \& Management, 5(1), 1-11.

Labbé, M., \& Hakimi, S. L. (1991). Market and locational equilibrium for two competitors. Operations Research, 39(5), 749-756.

Labbé, M., Marcotte, P., \& Savard, G. (1998). A bilevel model of taxation and its application to optimal highway pricing. Management Science, 44(12-part-1), 1608-1622.

LeBlanc, L. J., Morlok, E. K., \& Pierskalla, W. P. (1975). An efficient approach to solving the road network equilibrium traffic assignment problem. Transportation Research, 9(5), 309-318.

Lee, C.-Y., \& Song, D.-P. (2017). Ocean container transport in global supply chains: Overview and research opportunities. Transportation Research Part B: Methodological, 95, 442-474.

Lei, C., \& Ouyang, Y. (2017). Dynamic pricing and reservation for intelligent urban parking management. Transportation Research Part C: Emerging Technologies, 77, 226-244.

Littlechild, S. C., \& Thompson, G. (1977). Aircraft landing fees: A game theory approach. The Bell Journal of Economics, 186-204.

Mandell, S., \& Proost, S. (2016). Why truck distance taxes are contagious and drive fuel taxes to the bottom. Journal of Urban Economics, 93, 1-17.

Marcotte, P. (1985). A new algorithm for solving variational inequalities with application to the traffic assignment problem. Mathematical Programming, 33(3), 339-351.

Martín, J. C., \& Román, C. (2003). Hub location in the south-atlantic airline market: A spatial competition game. Transportation Research Part A: Policy and Practice, 37(10), 865-888.

Maschler, M., Peleg, B., \& Shapley, L. S. (1979). Geometric properties of the kernel, nucleolus, and related solution concepts. Mathematics of Operations Research, 4(4), 303-338.

Mathisen, T. A., \& Solvoll, G. (2008). Competitive tendering and structural changes: An example from the bus industry. Transport Policy, 15(1), 1-11. 
McFadden, D. (1973). Conditional logit analysis of qualitative choice behaviour. In P. Zarembka (Ed.), Frontiers in econometrics (pp. 105-142). New York: Academic Press.

McFadden, D. (1978). Modeling the choice of residential location. Transportation Research Record, (673).

Milakis, D., Kroesen, M., \& van Wee, B. (2018). Implications of automated vehicles for accessibility and location choices: Evidence from an expert-based experiment. Journal of Transport Geography, 68, 142-148.

Milgrom, P., et al. (1987). Auction theory. In Advances in economic theory: Fifth world congress: 1 (p. 32). Cambridge Univ. Press Cambridge.

Miller, T. C., Tobin, R. L., \& Friesz, T. L. (1991). Stackelberg games on a network with cournot-nash oligopolistic competitors. Journal of Regional Science, 31(4), 435-454.

Monderer, D., \& Shapley, L. S. (1996). Potential games. Games and Economic Behavior, 14(1), 124-143.

Myerson, R. B. (1978). Refinements of the Nash equilibrium concept. International Journal of Game Theory, 7(2), 73-80.

Nagurney, A., \& Ramanujam, P. (1996). Transportation network policy modeling with goal targets and generalized penalty functions. Transportation Science, 30(1), 3-13.

Nash, J. (1950). The bargaining problem. Econometrica: Journal of the Econometric Society, 155-162.

Nash, J. (1951). Non-cooperative games. Annals of Mathematics, 286-295.

Nash, J. (1953). Two-person cooperative games. Econometrica: Journal of the Econometric Society, 128-140.

Nash, J. F., et al. (1950). Equilibrium points in n-person games. Proceedings of the National Academy of Sciences, 36(1), 48-49.

Neuhoff, K., Barquin, J., Boots, M. G., Ehrenmann, A., Hobbs, B. F., Rijkers, F. A., \& Vazquez, M. (2005). Network-constrained Cournot models of liberalized electricity markets: The devil is in the details. Energy Economics, 27(3), 495525.

Nisan, N., Roughgarden, T., Tardos, E., \& Vazirani, V. V. (2007). Algorithmic game theory. Cambridge university press.

O'Kelly, M. E. (1987). A quadratic integer program for the location of interacting hub facilities. European Journal of Operational Research, 32(3), 393-404.

O'Kelly, M. E. (1992). Hub facility location with fixed costs. Papers in Regional Science, 71(3), 293-306.

Patriksson, M. (2015). The traffic assignment problem: models and methods. Courier Dover Publications.

Perennes, P. (2014). Use of combinatorial auctions in the railway industry: Can the "invisible hand" draw the railway timetable? Transportation Research Part A: Policy and Practice, 67, 175-187.

Pita, J. P., Adler, N., \& Antunes, A. P. (2014). Socially-oriented flight scheduling and fleet assignment model with an application to norway. Transportation Research Part B: Methodological, 61, 17-32.

Poorzahedy, H., \& Rouhani, O. M. (2007). Hybrid meta-heuristic algorithms for solving network design problem. European Journal of Operational Research, 182(2), 578-596.

Proost, S., \& Thisse, J.-F. (2019). What can be learned from spatial economics? Journal of Economic Literature, 57(3), 575-643.

Raturi, V., \& Verma, A. (2019). Competition between high speed rail and conventional transport modes: Market entry game analysis on indian corridors. Networks and Spatial Economics, 19(3), 763-790.

Ropke, S., \& Pisinger, D. (2006). An adaptive large neighborhood search heuristic for the pickup and delivery problem with time windows. Transportation Science, 40(4), 455-472.

Rosenthal, R. W. (1973). A class of games possessing pure-strategy Nash equilibria. International Journal of Game Theory, 2(1), 65-67.

Roth, A. E., \& Erev, I. (1995). Learning in extensive-form games: Experimental data and simple dynamic models in the intermediate term. Games and Economic Behavior, 8(1), 164-212.

Roumboutsos, A., \& Kapros, S. (2008). A game theory approach to urban public transport integration policy. Transport Policy, 15(4), 209-215.

Rubinstein, A., \& Wolinsky, A. (1994). Rationalizable conjectural equilibrium: between Nash and rationalizability. Games and Economic Behavior, 6(2), 299311

Ruiz-Rúa, A., \& Palacín, R. (2013). Towards a liberalised european high speed railway sector: Analysis and modelling of competition using game theory. European Transport Research Review, 5(1), 53-63.

Saeed, N., \& Larsen, O. I. (2010). An application of cooperative game among container terminals of one port. European Journal of Operational Research, 203(2), 393-403.

Salop, S. C. (1979). Monopolistic competition with outside goods. The Bell Journal of Economics, 10(1), 141-156.

Samuelson, W., \& Zeckhauser, R. (1988). Status quo bias in decision making. Journal of Risk and Uncertainty, 1(1), 7-59.

Sandler, T. (1992). Collective action: Theory and applications. University of Michigan Press.

Scheltes, A., \& de Almeida Correia, G. H. (2017). Exploring the use of automated vehicles as last mile connection of train trips through an agent-based simulation model: An application to delft, netherlands. International Journal of Transportation Science and Technology, 6(1), 28-41.

Schiewe, A., Schiewe, P., \& Schmidt, M. (2019). The line planning routing game, European Journal of Operational Research, 274(2), 560-573.

Schipper, Y., Nijkamp, P., \& Rietveld, P. (2007). Deregulation and welfare in airline markets: An analysis of frequency equilibria. European Journal of Operational Research, 178(1), 194-206.
Schmeidler, D. (1969). The nucleolus of a characteristic function game. SIAM Journal on Applied Mathematics, 17(6), 1163-1170.

Selten, R. (1975). Re-examination of the perfectness concept for equilibrium points in extensive games. International Journal of Game Theory, 4, 25-55.

Shapley, L. S. (1953a). Stochastic games. Proceedings of the National Academy of Sciences, 39(10), 1095-1100.

Shapley, L. S. (1953b). A value for n-person games. Contributions to the Theory of Games, 2(28), 307-317.

Shen, Y., Zhang, H., \& Zhao, J. (2018). Integrating shared autonomous vehicle in public transportation system: A supply-side simulation of the first-mile service in singapore. Transportation Research Part A: Policy and Practice, 113, 125-136.

Sherali, H. D., \& Lunday, B. J. (2011). Equitable apportionment of railcars within a pooling agreement for shipping automobiles. Transportation Research Part E: Logistics and Transportation Review, 47(2), 263-283.

Sherali, H. D., Soyster, A. L., \& Murphy, F. H. (1983). Stackelberg-Nash-Cournot equilibria: Characterizations and computations. Operations Research, 31(2), 253-276.

Shoham, Y., \& Leyton-Brown, K. (2008). Teams of selfish agents: An introduction to coalitional game theory (pp. 367-392)). Cambridge University Press.

Shoup, D. C. (2006). Cruising for parking. Transport Policy, 13(6), 479-486.

Simon, H. A. (1972). Theories of bounded rationality. Decision and Organization, 1(1), 161-176.

Small, K. A. (2015). The bottleneck model: An assessment and interpretation. Economics of Transportation, 4(1-2), 110-117.

Small, K. A., \& Rosen, H. S. (1981). Applied welfare economics with discrete choice models. Econometrica (pre-1986), 49(1), 105.

Song, D.-W., \& Panayides, P. M. (2002). A conceptual application of cooperative game theory to liner shipping strategic alliances. Maritime Policy \& Management, 29(3), 285-301.

Stopher, P. R. (2004). Reducing road congestion: a reality check. Transport Policy, 11(2), 117-131.

Sun, L.-J., \& Gao, Z.-Y. (2007). An equilibrium model for urban transit assignment based on game theory. European Journal of Operational Research, 181(1), 305-314

Sun, M., Aronson, J. E., McKeown, P. G., \& Drinka, D. (1998). A tabu search heuristic procedure for the fixed charge transportation problem. European Journal of Operational Research, 106(2-3), 441-456.

Talebian, A., \& Zou, B. (2016). A multi-stage approach to air-rail competition: Focus on rail agency objective, train technology and station access. Journal of Rail Transport Planning \& Management, 6(1), 48-66.

Train, K. E. (2009). Discrete choice methods with simulation. Cambridge university press.

Tukiainen, J. (2008). Testing for common costs in the city of helsinki bus transit auctions. International Journal of Industrial Organization, 26(6), 1308-1322.

Ubbels, B., \& Verhoef, E. T. (2008). Auctioning concessions for private roads. Transportation Research Part A: Policy and Practice, 42(1), 155-172.

van Nieuwkoop, R. H., Axhausen, K. W., \& Rutherford, T. F. (2016). A traffic equilibrium model with paid-parking search. Journal of Transport Economics and Policy (JTEP), 50(3), 262-286.

Van Vliet, D. (1987). The frank-wolfe algorithm for equilibrium traffic assignment viewed as a variational inequality. Transportation Research Part B: Methodological, 21(1), 87-89.

Vaze, V., \& Barnhart, C. (2012). Modeling airline frequency competition for airport congestion mitigation. Transportation Science, 46(4), 512-535.

Vaze, V., \& Harder, R. (2012). A game-theoretic modeling approach to air traffic forecasting. In Twelfth USA/Europe air traffic management research and development seminar (ATM2017).

Verhoef, E. T. (2007). Second-best road pricing through highway franchising. Journal of Urban Economics, 62(2), 337-361.

Vicente, L. N., \& Calamai, P. H. (1994). Bilevel and multilevel programming: A bibliography review. Journal of Global optimization, 5(3), 291-306.

Vickrey, W. S. (1969). Congestion theory and transport investment. The American Economic Review, 59(2), 251-260.

Von Neuman, J., \& Morgenstern, O. (1944). Theory of Games and Economic Behavior. Princeton University Press.

Von Stackelberg, H. F. (1934). Marktform und Gleichgewicht.

Von Stackelberg, H. F. (2010). Market structure and equilibrium (translation by Damien Bazin). Springer Science \& Business Media.

Wang, S., Fan, J., Zhao, D., \& Wu, Y. (2015). The impact of government subsidies or penalties for new-energy vehicles a static and evolutionary game model analysis. Journal of Transport Economics and Policy (JTEP), 49(1), 98-114.

Wardrop, J. G. (1952). Road paper. some theoretical aspects of road traffic research.. Proceedings of the Institution of Civil Engineers, 1(3), 325-362.

Weinberger, R. (2012). Death by a thousand curb-cuts: Evidence on the effect of minimum parking requirements on the choice to drive. Transport Policy, 20, 93-102.

Weitzman, M. L. (1974). Prices vs. quantities. The Review of Economic Studies, 41(4), 477-491.

Wie, B.-W. (1993). A differential game model of Nash equilibrium on a congested traffic network. Networks, 23(6), 557-565.

Willson, R. W., \& Shoup, D. C. (1990). Parking subsidies and travel choices: assessing the evidence. Transportation, 17(2), 141-157.

Xu, M., Wang, G., Grant-Muller, S., \& Gao, Z. (2017). Joint road toll pricing and capacity development in discrete transport network design problem. Transportation, 44(4), 731-752.

Yamada, T., Russ, B. F., Castro, J., \& Taniguchi, E. (2009). Designing multimodal freight transport networks: A heuristic approach and applications. Transportation Science, 43(2), 129-143. 
Yang, H., \& Zhang, A. (2012). Effects of high-speed rail and air transport competition on prices, profits and welfare. Transportation Research Part B: Methodological, 46(10), 1322-1333.

Zhang, H., Su, Y., Peng, L., \& Yao, D. (2010). A review of game theory applications in transportation analysis. In 2010 international conference on computer and information application (pp. 152-157). IEEE.
Zhou, W.-H., \& Lee, C.-Y. (2009). Pricing and competition in a transportation market with empty equipment repositioning. Transportation Research Part B: Methodological, 43(6), 677-691.

Zou, B., \& Hansen, M. (2012). Flight delays, capacity investment and social welfare under air transport supply-demand equilibrium. Transportation Research Part A: Policy and Practice, 46(6), 965-980. 